\title{
Racial, Ethnic, and Gender Equity in Veteran Satisfaction with Health Care in the Veterans Affairs Health Care System
}

\author{
Susan L. Zickmund, PhD ${ }^{1,2}$, Kelly H. Burkitt, PhD ${ }^{3}$, Shasha Gao, PhD ${ }^{3}$, Roslyn A. Stone, PhD ${ }^{3,4}$, \\ Audrey L. Jones, $P h D^{1,2}$, Leslie R. M. Hausmann, PhD ${ }^{3,5}$, Galen E. Switzer, $P h D^{3,5,6}$, \\ Sonya Borrero, $P h D^{3,5}$, Keri L. Rodriguez, $P h D^{3,5}$, and Michael J. Fine, MD, MSc $c^{3,5}$
}

\begin{abstract}
'Informatics, Decision-Enhancement and Analytic Sciences Center (IDEAS 2.0), VA Salt Lake City Health Care System, Salt Lake City, UT, USA; ${ }^{2}$ Division of Epidemiology, Department of Internal Medicine, University of Utah School of Medicine, Salt Lake City, UT, USA; ${ }^{3}$ Center for Health Equity Research and Promotion, VA Pittsburgh Healthcare System, Pittsburgh, PA, USA; ${ }^{4}$ Department of Biostatistics, University of Pittsburgh Graduate School of Public Health, Pittsburgh, PA, USA; ${ }^{5}$ Division of General Internal Medicine, Department of Medicine, University of Pittsburgh School of Medicine, Pittsburgh, PA, USA; ${ }^{6}$ Department of Psychiatry, University of Pittsburgh School of Medicine, Pittsburgh, PA, USA.
\end{abstract}

BACKGROUND: Patient satisfaction is an important dimension of health care quality. The Veterans Health Administration (VA) is committed to providing high-quality care to an increasingly diverse patient population.

OBJECTIVE: To assess Veteran satisfaction with VA health care by race/ethnicity and gender.

DESIGN AND PARTICIPANTS: We conducted semistructured telephone interviews with gender-specific stratified samples of black, white, and Hispanic Veterans from 25 predominantly minority-serving VA Medical Centers from June 2013 to January 2015.

MAIN MEASURES: Satisfaction with health care was assessed in 16 domains using five-point Likert scales. We compared the proportions of Veterans who were very satisfied, somewhat satisfied, and less than satisfied (i.e., neither satisfied nor dissatisfied, somewhat dissatisfied, or very dissatisfied) in each domain, and used randomeffects multinomial regression to estimate racial/ethnic differences by gender and gender differences by race/ethnicity.

KEYRESULTS: Interviews were completed for 1222 of the 1929 Veterans known to be eligible for the interview (63.3\%), including 421 white, 389 black, and 396 Hispanic Veterans, 616 of whom were female. Veterans were less likely to be somewhat satisfied or less than satisfied versus very satisfied with care in each of the 16 domains. The highest satisfaction ratings were reported for costs, outpatient facilities, and pharmacy (74-76\% very satisfied); the lowest ratings were reported for access, pain management, and mental health care $(21-24 \%$ less than satisfied). None of the joint tests of racial/ethnic or gender differences in satisfaction (simultaneously comparing all three satisfaction levels) was statistically significant $(p>0.05)$. Pairwise comparisons of specific levels of satisfaction revealed racial/ethnic differences by gender in three domains and gender differences by race/ethnicity in five domains, with no consistent directionality across demographic subgroups.

Received June 9, 2017

Revised October 5, 2017

Accepted November 2, 2017

Published online January 8, 2018
CONCLUSIONS: Our multisite interviews of a diverse sample of Veterans at primarily minority-serving sites showed generally high levels of health care satisfaction across 16 domains, with few quantitative differences by race/ethnicity or gender.

KEY WORDS: patient satisfaction; health care disparities; veterans.

J Gen Intern Med 33(3):305-31

DOI: $10.1007 / \mathrm{s} 11606-017-4221-9$

(C) Society of General Internal Medicine (outside the USA) 2018

\section{INTRODUCTION}

Patient satisfaction is an important dimension of health care quality, with meaningful secondary benefits. ${ }^{1,2}$ Patients who are more satisfied with their care are more likely to demonstrate positive health behaviors, such as improved self-care, increased adherence to prescribed medications, and acceptance of provider recommendations. ${ }^{3,4}$ Measures of patient satisfaction are used to grade the effectiveness of medical providers and health care systems, ${ }^{5}$ and are increasingly linked to provider and hospital payments. ${ }^{6}$

As the largest integrated health care system in the United States (US), the Veterans Health Administration (VA) systematically tracks patient satisfaction through the national Survey of Health care Experiences of Patients (SHEP), ${ }^{7,8}$ and is committed to operating a "health care network that anticipates and meets the needs of enrolled Veterans, in general ... and the most vulnerable Veterans, in particular." 9 While satisfaction ratings assess the extent to which patients are happy with care, measures of health care experiences assess how frequently positive interactions with care occur (e.g., how often providers listen carefully). ${ }^{10,11}$ Measures of health care experiences are less subjective measures of health care quality. ${ }^{11}$ Prior studies of racial/ethnic and gender differences in VA health care experiences have revealed some inequities among these vulnerable patient populations, with no consistent pattern of differences across studies. . $^{2,7,12-14}$

In studies of racial/ethnic differences, black and Hispanic Veterans have reported more negative and fewer positive health care experiences than whites, ${ }^{7,12,13}$ with a majority of 
the observed differences attributed to between-facility variations in experiences with care. ${ }^{7,12}$ Gender differences in VA health care experience have been less consistently documented, with some studies reporting lower satisfaction among female Veterans, particularly for inpatient care, ${ }^{8}$ while others reported no gender differences in patient experience ${ }^{12}$ or reported more positive experiences among female Veterans in some domains of outpatient care. ${ }^{12}$

Previous studies of racial/ethnic and gender differences in health care satisfaction among Veterans were based on small samples, ${ }^{2}$ assessed experiences in a limited set of health care domains, ${ }^{15-17}$ or were conducted prior to recent VA initiatives aimed at making the health care environment more welcoming to female Veterans. ${ }^{8,18}$ To better understand racial/ethnic and gender variations in health care satisfaction, we conducted a large mixed-methods evaluation of Veteran satisfaction with outpatient, inpatient, and specialist care in a diverse sample of Veterans from predominantly minority-serving VA Medical Centers (VAMCs). In this report, we compare satisfaction ratings by race/ethnicity and gender.

\section{METHODS}

\section{Design}

We identified potential participants from 25 VAMCs across the US, conducted a multi-step recruitment and consent process between June 2013 and January 2015, and interviewed eligible participants by telephone within 6 weeks of obtaining their written consent. Study procedures were approved by the local institutional review board.

\section{Facility Selection}

Preliminary analyses indicated that the majority of racial/ ethnic minority Veterans $(75 \%)$ received their VA health care at a relatively small number of VAMCs $(25 \%)$. We used VA administrative data from fiscal year (FY) 2009 (October 2008 to September 2009) to identify 43 VAMCs that provided care to $70 \%$ of black and/or Hispanic Veterans in the US. From these facilities, we selected a diverse set of VAMCs, including 10 where the patient population was at least $30 \%$ black and/or Hispanic, 44 where $10 \%$ or fewer were black and/or Hispanic, and 11 that were chosen to ensure a diversity in size and geographic location. Characteristics of participating sites are summarized in Appendix 1.

\section{Sampling}

We used administrative records to identify Veterans with at least one outpatient visit at a participating VAMC in FY 2012 or 2013, excluding Veterans without valid contact information. From those eligible, we randomly selected 90 Veterans from each facility in each of six strata (i.e., non-Hispanic white, non-Hispanic black, Hispanic male, non-Hispanic white, non-Hispanic black, or Hispanic female), resulting in an initial sampling frame of 13,500 Veterans. In facilities with fewer than 90 Veterans per stratum, we randomly sampled Veterans of the same gender with unknown race or ethnicity.

\section{Recruitment}

Potentially eligible Veterans were mailed a brief study description with an option to opt out of screening by telephone or mail. We called Veterans who did not opt out to confirm study eligibility, excluding those who did not speak English or declined to self-report race, ethnicity, or gender. Once written informed consent was obtained, eligible participants were interviewed by a contracted professional survey research organization.

Recruitment was conducted in waves over time. In each wave, a stratified random sample of several hundred Veterans was drawn from the initial sampling frame. We discontinued recruitment within a facility-specific stratum when a target sample size of nine Veterans was achieved. We chose this target based on the feasibility of interviewing an adequate number of respondents within each stratum per site to achieve qualitative thematic saturation. Respondents received a \$35 honorarium for participation.

\section{Health Care Satisfaction}

Our mixed-methods study obtained quantitative Likert-style satisfaction ratings and asked qualitative open-ended questions to ascertain patient experiences that influenced satisfaction ratings. Standard measures of patient experience typically focus on frequency of specific experiences when obtaining care and not on patient evaluations of whether these experiences were deemed satisfactory. The analysis below focuses on quantitative satisfaction ratings. Appendix 2 contains the full interview script.

We assessed satisfaction with care in 16 domains based on the VA's validated $\mathrm{SHEP}^{7,8}$ and prior research, ${ }^{19}$ including overall, outpatient, and inpatient care; primary care, specialist, and mental health providers; provider communication and respect, coordination of care, physical facilities (main VAMCs, local outpatient clinics), cost of care, pharmacy, pain management, and women's health. Lead-in questions ascertained domain applicability. For each applicable domain, patient satisfaction was assessed using a single item with a fivecategory Likert scale (i.e., very satisfied, somewhat satisfied, neither satisfied nor dissatisfied, somewhat dissatisfied, and very dissatisfied). We combined Likert responses in the three lowest categories due to sparse data, and classified this combined category as "less than satisfied."

\section{Race/Ethnicity, Gender, and Covariates}

We classified race/ethnicity obtained from the interview as non-Hispanic white, non-Hispanic black, Hispanic, or other, and gender as male or female. The interview also assessed sociodemographic characteristics (Table 1). We assessed 
Table 1. Respondent Demographic, Clinical, and Health Care Utilization Characteristics by Race/Ethnicity and Gender

\begin{tabular}{|c|c|c|c|c|c|c|c|c|c|c|c|c|}
\hline \multirow{3}{*}{$\begin{array}{l}\text { Characteristics } \\
\text { Age in years (mean, } \mathrm{SD})^{*}\end{array}$} & \multicolumn{4}{|c|}{ White $(N=421)$} & \multicolumn{4}{|c|}{ Black $(N=389)$} & \multicolumn{4}{|c|}{ Hispanic $(N=396)$} \\
\hline & \multicolumn{2}{|c|}{$\begin{array}{l}\text { Male } \\
(N=208)\end{array}$} & \multicolumn{2}{|c|}{$\begin{array}{l}\text { Female } \\
(N=213)\end{array}$} & $\begin{array}{l}\text { Male } \\
(N=\end{array}$ & 87) & $\begin{array}{l}\text { Fema } \\
(N=\end{array}$ & & $\begin{array}{l}\text { Male } \\
(N=\end{array}$ & & $\begin{array}{l}\text { Fema } \\
(N=\end{array}$ & $\begin{array}{l}e \\
\text { 201) }\end{array}$ \\
\hline & 65.7 & 6.76 & 55.1 & 6.39 & 59.7 & 5.63 & 50.1 & 6.06 & 57.0 & 7.29 & 44.9 & 6.27 \\
\hline $\begin{array}{l}\text { Marital status }(n, \%)^{*} \\
\text { Married/livino }\end{array}$ & & & & & & & & & & & & \\
\hline Married/living as married & 67 & 32.2 & 123 & 57.7 & 105 & 56.1 & 151 & 74.8 & 79 & 40.5 & 117 & 58.2 \\
\hline $\begin{array}{l}\text { Single/widowed/divorced/separated } \\
\text { Education level }(n \% \text { ) }\end{array}$ & 141 & 67.8 & 89 & 41.8 & 82 & 43.9 & 51 & 25.2 & 116 & 59.5 & 83 & 41.3 \\
\hline Education level $(n, \%)^{*}$ & & & & & & & & & & & & \\
\hline$\leq$ High school/GED & 43 & 20.7 & 15 & 7.0 & 46 & 24.6 & 11 & 5.4 & 47 & 24.1 & 20 & 10.0 \\
\hline Trade school/some college & 79 & 38.0 & 96 & 45.1 & 94 & 50.3 & 94 & 46.5 & 93 & 47.7 & 87 & 43.3 \\
\hline$\geq$ College graduate & 83 & 39.9 & 97 & 45.5 & 47 & 25.1 & 94 & 46.5 & 55 & 28.2 & 93 & 46.3 \\
\hline Employment status $(n, \%) *$ & & & & & & & & & & & & \\
\hline Full-time & 37 & 17.8 & 56 & 26.3 & 29 & 15.5 & 79 & 39.1 & 53 & 27.2 & 83 & 41.3 \\
\hline Part-time & 24 & 11.5 & 27 & 12.7 & 16 & 8.6 & 15 & 7.4 & 14 & 7.2 & 25 & 12.4 \\
\hline Unemployed/homemaker/student & 12 & 5.8 & 30 & 14.1 & 21 & 11.2 & 36 & 17.8 & 24 & 12.3 & 45 & 22.4 \\
\hline Retired & 118 & 56.7 & 60 & 28.2 & 76 & 40.6 & 33 & 16.3 & 73 & 37.4 & 27 & 13.4 \\
\hline Disabled & 16 & 7.7 & 39 & 18.3 & 44 & 23.5 & 38 & 18.8 & 31 & 15.9 & 21 & 10.4 \\
\hline Place of residence $(n, \%)^{*}$ & & & & & & & & & & & & \\
\hline Own home & 149 & 71.6 & 138 & 64.8 & 85 & 45.5 & 86 & 42.6 & 119 & 61.0 & 94 & 46.8 \\
\hline Rented home/apartment & 42 & 20.2 & 52 & 24.4 & 77 & 41.2 & 100 & 49.5 & 59 & 30.3 & 91 & 45.3 \\
\hline Shared or no permanent housing & 17 & 8.2 & 21 & 9.9 & 24 & 12.8 & 15 & 7.4 & 16 & 8.2 & 15 & 7.5 \\
\hline Children in household $(n, \%)^{*}$ & 25 & 12.0 & 52 & 24.4 & 32 & 17.1 & 69 & 34.2 & 60 & 30.8 & 77 & 38.3 \\
\hline Income $(n, \%)^{\dagger}$ & & & & & & & & & & & & \\
\hline$\leq \$ 19,999$ & 44 & 21.2 & 52 & 24.4 & 70 & 37.4 & 44 & 21.8 & 45 & 23.1 & 45 & 22.4 \\
\hline$\geq \$ 20,000$ to $\$ 49,999$ & 87 & 41.8 & 93 & 43.7 & 64 & 34.2 & 84 & 41.6 & 90 & 46.2 & 75 & 37.3 \\
\hline$\geq \$ 50,000$ & 69 & 33.2 & 62 & 29.1 & 49 & 26.2 & 68 & 33.7 & 54 & 27.7 & 72 & 35.8 \\
\hline Rural/highly rural $(n, \%)^{*}$ & 100 & 48.1 & 95 & 44.6 & 52 & 27.8 & 56 & 27.7 & 71 & 36.4 & 74 & 36.8 \\
\hline Military service era $(n, \%)$ & & & & & & & & & & & & \\
\hline Pre-Vietnam* & 63 & 30.3 & 15 & 7.0 & 16 & 8.6 & 7 & 3.5 & 16 & 8.2 & 3 & 1.5 \\
\hline Vietnam War* & 119 & 57.2 & 67 & 31.5 & 103 & 55.1 & 29 & 14.4 & 97 & 49.7 & 22 & 10.9 \\
\hline Post-Vietnam* & 54 & 26.0 & 116 & 54.5 & 98 & 52.4 & 124 & 61.4 & 74 & 37.9 & 84 & 41.8 \\
\hline Persian Gulf* & 39 & 18.8 & 96 & 45.1 & 52 & 27.8 & 130 & 64.4 & 72 & 36.9 & 150 & 74.6 \\
\hline Health status $(n, \%) *$ & & & & & & & & & & & & \\
\hline Poor & 22 & 10.6 & 16 & 7.5 & 21 & 11.2 & 16 & 7.9 & 20 & 10.3 & 18 & 9.0 \\
\hline Fair & 33 & 15.9 & 38 & 17.8 & 54 & 28.9 & 59 & 29.2 & 58 & 29.7 & 43 & 21.4 \\
\hline Good & 79 & 38.0 & 73 & 34.3 & 73 & 39.0 & 87 & 43.1 & 64 & 32.8 & 72 & 35.8 \\
\hline Very good & 50 & 24.0 & 70 & 32.9 & 34 & 18.2 & 30 & 14.9 & 40 & 20.5 & 54 & 26.9 \\
\hline Excellent & 24 & 11.5 & 15 & 7.0 & 4 & 2.1 & 10 & 5.0 & 13 & 6.7 & 14 & 7.0 \\
\hline Health compared to 1 year ago $(n, \%)^{\ddagger}$ & & & & & & & & & & & & \\
\hline Much worse & 11 & 5.3 & 12 & 5.6 & 8 & 4.3 & 10 & 5.0 & 7 & 3.6 & 11 & 5.5 \\
\hline Somewhat worse & 55 & 26.4 & 33 & 15.5 & 30 & 16.0 & 31 & 15.3 & 47 & 24.1 & 44 & 21.9 \\
\hline About the same & 99 & 47.6 & 94 & 44.1 & 92 & 49.2 & 99 & 49.0 & 75 & 38.5 & 88 & 43.8 \\
\hline Somewhat better & 18 & 8.7 & 45 & 21.1 & 29 & 15.5 & 30 & 14.9 & 28 & 14.4 & 26 & 12.9 \\
\hline Much better & 25 & 12.0 & 28 & 13.1 & 28 & 15.0 & 32 & 15.8 & 37 & 19.0 & 32 & 15.9 \\
\hline Confidence with medical forms $(n, \%) *$ & & & & & & & & & & & & \\
\hline Not at all/A little bit/Somewhat & 20 & 9.8 & 10 & 4.7 & 12 & 6.6 & 10 & 5.0 & 22 & 11.6 & 11 & 5.5 \\
\hline Quite a bit & 31 & 15.2 & 14 & 6.6 & 34 & 18.6 & 15 & 7.5 & 38 & 20.0 & 14 & 7.0 \\
\hline Extremely & 153 & 75.0 & 187 & 88.6 & 137 & 74.9 & 176 & 87.6 & 130 & 68.4 & 176 & 87.6 \\
\hline Comorbid conditions $(n, \%)$ & & & & & & & & & & & & \\
\hline Asthma & 33 & 15.9 & 49 & 23.0 & 36 & 19.3 & 47 & 23.3 & 36 & 18.5 & 42 & 20.9 \\
\hline Arthritis & 114 & 54.8 & 125 & 58.7 & 107 & 57.2 & 115 & 56.9 & 97 & 49.7 & 85 & 42.3 \\
\hline Cancer* & 29 & 13.9 & 14 & 6.6 & 11 & 5.9 & 5 & 2.5 & 15 & 7.7 & 4 & 2.0 \\
\hline Diabetes* & 53 & 25.5 & 26 & 12.2 & 63 & 33.7 & 43 & 21.3 & 61 & 31.3 & 30 & 14.9 \\
\hline Digestive or GI problems ${ }^{\dagger}$ & 36 & 17.3 & 54 & 25.4 & 30 & 16.0 & 59 & 29.2 & 33 & 16.9 & 47 & 23.4 \\
\hline Heart disease* & 53 & 25.5 & 21 & 9.9 & 30 & 16.0 & 22 & 10.9 & 39 & 20.0 & 14 & 7.0 \\
\hline HIV or AIDS & 4 & 1.9 & 0 & 0.0 & 5 & 2.7 & 3 & 1.5 & 5 & 2.6 & 0 & 0.0 \\
\hline Kidney disease ${ }^{\dagger}$ & 12 & 5.8 & 5 & 2.3 & 16 & 8.6 & 7 & 3.5 & 11 & 5.6 & 1 & 0.5 \\
\hline Liver problem & 17 & 8.2 & 6 & 2.8 & 20 & 10.7 & 10 & 5.0 & 17 & 8.7 & 9 & 4.5 \\
\hline Stroke or mini-stroke & 20 & 9.6 & 15 & 7.0 & 10 & 5.3 & 9 & 4.5 & 16 & 8.2 & 6 & 3.0 \\
\hline Depression* & 64 & 30.8 & 94 & 44.1 & 77 & 41.2 & 99 & 49.0 & 88 & 45.1 & 103 & 51.2 \\
\hline PTSD or anxiety disorder* & 57 & 27.4 & 99 & 46.5 & 79 & 42.2 & 107 & 53.0 & 94 & 48.2 & 105 & 52.2 \\
\hline Number of comorbid conditions $(n, \%)$ & & & & & & & & & & & & \\
\hline 0 & 32 & 15.4 & 22 & 10.3 & 26 & 13.9 & 32 & 15.8 & 23 & 11.8 & 40 & 19.9 \\
\hline 1 & 43 & 20.7 & 49 & 23.0 & 28 & 15.0 & 31 & 15.3 & 45 & 23.1 & 41 & 20.4 \\
\hline 2 & 45 & 21.6 & 51 & 23.9 & 50 & 26.7 & 39 & 19.3 & 32 & 16.4 & 38 & 18.9 \\
\hline 3 & 42 & 20.2 & 40 & 18.8 & 28 & 15.0 & 34 & 16.8 & 36 & 18.5 & 33 & 16.4 \\
\hline $4+$ & 46 & 22.1 & 50 & 23.5 & 55 & 29.4 & 66 & 32.7 & 59 & 30.3 & 49 & 24.4 \\
\hline VA health care systen & & & & & & & & & & & & \\
\hline Received all health care at $\mathrm{VA}^{\dagger}$ & 109 & 52.4 & 121 & 56.8 & 136 & 72.7 & 125 & 61.9 & 136 & 69.7 & 129 & 64.2 \\
\hline Pain management in last 24 months* & 90 & 43.3 & 127 & 59.6 & 112 & 59.9 & 152 & 75.2 & 102 & 52.3 & 125 & 62.2 \\
\hline Used VA pharmacy in last 24 months $^{\dagger}$ & 180 & 86.5 & 196 & 92.0 & 178 & 95.2 & 194 & 96.0 & 183 & 93.8 & 189 & 94.0 \\
\hline$\geq 1$ outpatient visit in last 12 months & 200 & 96.2 & 203 & 95.3 & 182 & 97.3 & 195 & 96.5 & 184 & 94.4 & 191 & 95.0 \\
\hline$\geq 1 \mathrm{PCP}$ visit in past 12 months & 190 & 91.3 & 188 & 88.3 & 175 & 93.6 & 188 & 93.1 & 175 & 89.7 & 182 & 90.5 \\
\hline$\geq 1 \mathrm{MH}$ visit in past 12 months* & 56 & 26.9 & 85 & 39.9 & 83 & 44.4 & 98 & 48.5 & 79 & 40.5 & 92 & 45.8 \\
\hline
\end{tabular}


Table 1.. (continued)

\begin{tabular}{|c|c|c|c|c|c|c|c|c|c|c|c|c|}
\hline \multirow{3}{*}{$\begin{array}{l}\text { Characteristics } \\
\text { Hospitalized in past } 12 \text { months }^{\dagger}\end{array}$} & \multicolumn{4}{|c|}{ White $(N=421)$} & \multicolumn{4}{|c|}{ Black $(N=389)$} & \multicolumn{4}{|c|}{ Hispanic $(N=396)$} \\
\hline & \multicolumn{2}{|c|}{$\begin{array}{l}\text { Male } \\
(N=208)\end{array}$} & \multicolumn{2}{|c|}{$\begin{array}{l}\text { Female } \\
(N=213)\end{array}$} & \multicolumn{2}{|c|}{$\begin{array}{l}\text { Male } \\
(N=187)\end{array}$} & \multicolumn{2}{|c|}{$\begin{array}{l}\text { Female } \\
(N=202)\end{array}$} & \multicolumn{2}{|c|}{$\begin{array}{l}\text { Male } \\
(N=195)\end{array}$} & \multicolumn{2}{|c|}{$\begin{array}{l}\text { Female } \\
(N=201)\end{array}$} \\
\hline & 20 & 9.6 & 26 & 12.2 & 38 & 20.3 & 25 & 12.4 & 20 & 10.3 & 15 & 7.5 \\
\hline Number of outpatient visits* (mean SD) & 14.7 & 8.67 & 18.4 & 10.71 & 22.5 & 13.93 & 24.8 & 13,31 & 21.2 & 14.55 & 17.4 & 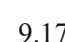 \\
\hline Number of primary care visits (mean SD) & 4.7 & 3.89 & 5.5 & 2.75 & 5.3 & 2.88 & 6.5 & 3.87 & 5.2 & 2.74 & 5.2 & 2.29 \\
\hline Number of mental health visits (mean SD) & 7.3 & 6.18 & 12.9 & 9.37 & 3.4 & 10.11 & 14.4 & 8.57 & 15.5 & 15.26 & 10.9 & 6.31 \\
\hline Hospital length of stay (mean SD) & 20.0 & 29.70 & 14.1 & 10.38 & 13.5 & 7.95 & 6.9 & 4.75 & 26.9 & 19.72 & 7.9 & 7.27 \\
\hline
\end{tabular}

Percentages are computed based on the column-specific denominators, and may not sum to 1 due to a small amount of missing data. Less than $1.5 \%$ of data are missing for marital status, education, employment status, place of residence, health status, health compared to 1 year ago, health literacy, and total number of self-reported comorbid conditions. For income, $3.2 \%$ of the observations are missing

Abbreviations: GED general equivalency diploma, GI gastrointestinal, MH mental health, PCP primary care provider, PTSD post-traumatic stress disorder, VA Department of Veterans Affairs

${ }^{*} p<0.001 ;{ }^{\dagger} p<0.01 ;{ }^{*} p<0.05$

health literacy using a single item (i.e., "How confident are you filling out medical forms by yourself: extremely, quite a bit, somewhat, a little bit, not at all?"). ${ }^{20}$ We quantified comorbidity using self-reported conditions from the Charlson Comorbidity Inde ${ }^{21}$ plus common mental health conditions among Veterans (i.e., depression, post-traumatic stress disorder [PTSD], and anxiety). We assessed health status using the single-item global health and 1-year prior health questions from the SF-36. ${ }^{22,23}$ We captured VA outpatient and inpatient health care utilization from VA administrative records in the 12 months prior to each participant's interview date.

\section{Statistical Analyses}

We summarized baseline respondent characteristics by race/ ethnicity and gender. We used chi-square statistics to compare categorical variables and analysis of variance to compare continuous variables, as shown in Table 1. We fit randomeffects multinomial regression models using the GLIMMIX procedure in SAS software (version 9.3; SAS Institute Inc., Cary, NC, USA) to compare the facility-specific proportions of participants who were "less than" or "somewhat" versus "very" satisfied (reference level) for each domain, specifying a random effect to account for clustering of Veterans within VAMCs.

Because preliminary analyses indicated a significant interaction between race/ethnicity and gender, we modeled genderspecific associations between race/ethnicity and satisfaction for each domain. Each model included fixed effects for gender, age (centered to the overall mean age [55] and scaled by 10 years), race/ethnicity, and the gender-by-race/ethnicity interaction, and a random effect for site. We adjusted for age in all models to account for differences in the age distributions by race/ethnicity. We assessed gender-specific differences between race/ethnicity subgroups using two-parameter 0.05 -level Wald tests that simultaneously compared "less than satisfied" and "somewhat satisfied" to "very satisfied"; we also report pairwise Wald tests comparing these response categories. We constructed gender-specific linear contrasts of satisfaction for black versus white and Hispanic versus white
Veterans, and race/ethnicity-specific contrasts from the same statistical model to assess gender differences within each race/ ethnicity category for all domains except women's health. $P$ values of $<0.05$ were considered statistically significant, with no adjustment made for multiple comparisons.

In a sensitivity analysis, we assessed potential confounding in the age-adjusted models by considering each of the covariates shown in Table 1. We included variables significant at the 0.10 level in the domain of outpatient care in all domain-specific multivariable models. For each domain-specific model, we then used a backwards selection approach (removing variables with $p>0.10$ ) to identify a parsimonious set of covariates. We assessed whether conclusions from the age-adjusted models changed based on this statistical adjustment for potential confounders.

\section{RESULTS}

\section{Recruitment}

Among the 7565 Veterans who were mailed invitations, 3090 (40.8\%) could not be contacted and 2063 (27.3\%) declined to be screened for eligibility (Appendix 3). Interviews were completed for 1222 of the 1929 Veterans known to be eligible for the study (63.3\%). Among those eligible, 531 (27.5\%) did not provide consent for voice recording, and 159 interviews $(8.2 \%)$ could not be completed before the end of the study. After excluding 16 Veterans with "other" self-reported race/ethnicity, our analytical sample included 1206 Veterans (421 white, 389 black, and 396 Hispanic), 616 of whom were women.

\section{Respondent Characteristics}

Black and Hispanic respondents were younger and served in more recent military service eras than did white respondents; they were also more likely to receive all of their medical care at the VA (Table 1). Compared to men of the same race/ethnicity, women were younger and more likely to be married, collegeeducated, employed full-time, living in households with children, and health-literate. Although some individual comorbid conditions were more prevalent in men than women (e.g., cancer, 


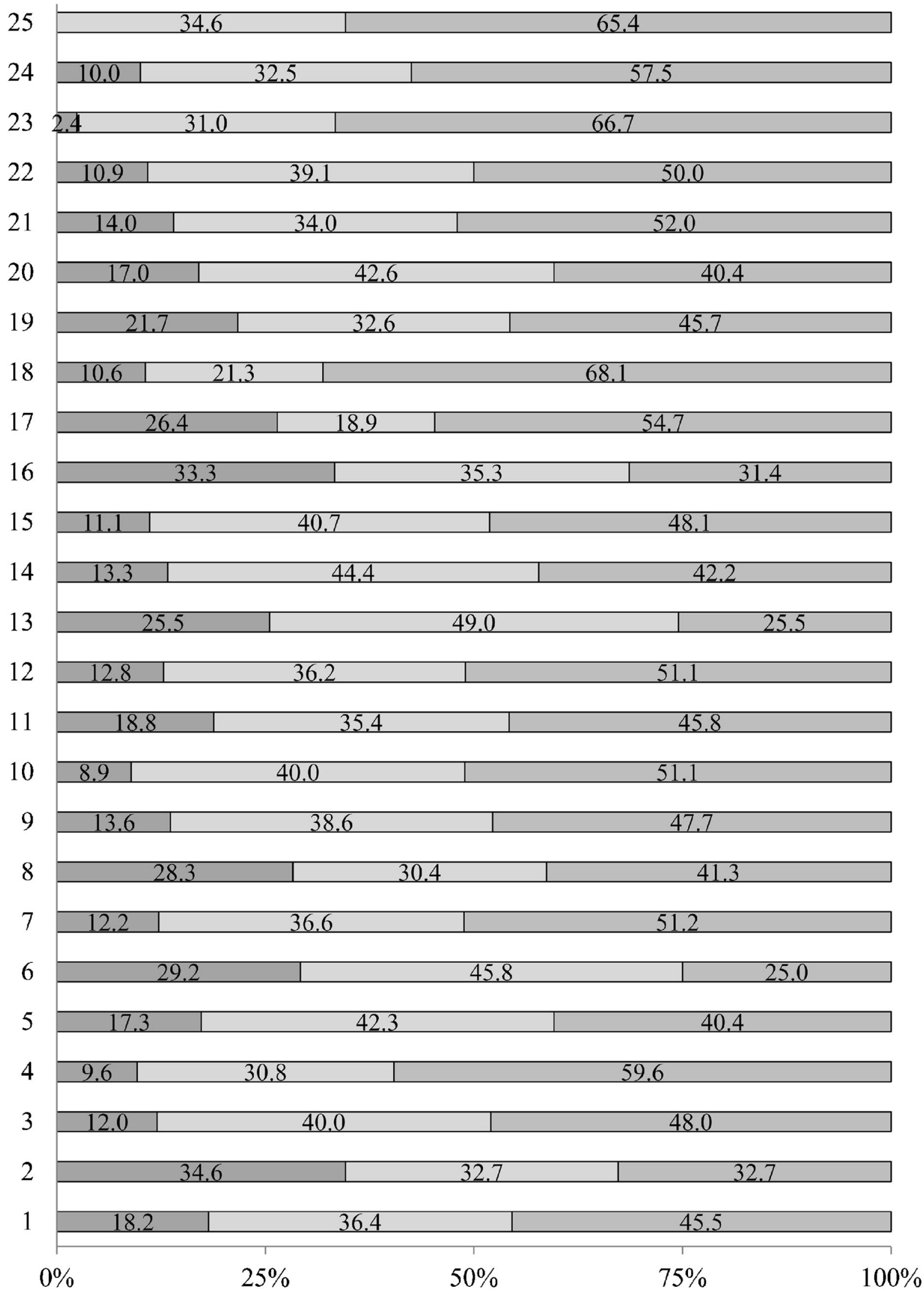

$\square$ Less than Satisfied $\square$ Somewhat Satisfied $\square$ Very Satisfied

Figure 1 Percentage of Veteran respondents less than satisfied, somewhat satisfied, and very satisfied with overall VA health care, by study facility. Facilities are numbered according to their documented percentage of white Veterans in the initial sampling frame, with 1 denoting the lowest percentage of whites $(23.3 \%)$, and 22-25 denoting the participating facilities with the highest percentages of whites (62.7-85.6\%, respectively). 
Overall care $(n=1196)$

Cost of care $(n=770)$

Physical facility $(\mathrm{CBOC}, \mathrm{n}=496)$

Pharmacy services $(n=1109)$

Inpatient care $(n=374)$

Respect $(\mathrm{n}=1104)$

Primary care provider $(n=1017)$

Specialist $(\mathrm{n}=870)$

Women's health $(\mathrm{n}=560)$

Physical facility (VAMC, $\mathbf{n}=1098$ )

Mental health services $(n=600)$

Outpatient care $(n=1134)$

Coordination of care $(n=1093)$

Communication $(n=1120)$

Pain management $(n=764)$

Access $(n=1126)$

\section{7}

36.0

47.2

\begin{tabular}{l|l|l}
10.3 & 13.4 & 76.4 \\
\hline
\end{tabular}

\section{2}

\begin{tabular}{l|l|l}
\hline 8.6 & 17.7 & 73.8 \\
\hline
\end{tabular}

\begin{tabular}{l|l|l}
\hline 12.6 & 15.5 & 71.9 \\
\hline
\end{tabular}

\begin{tabular}{r|r|r}
\hline 11.0 & 18.8 & 70.2 \\
\hline
\end{tabular}

\begin{tabular}{l|l|l}
12.0 & 18.0 & 70.0 \\
\hline
\end{tabular}

\begin{tabular}{l|l|l}
\hline 11.1 & 18.9 & 70.0 \\
\hline
\end{tabular}

\begin{tabular}{l|l|l}
15.4 & 20.4 & 64.3 \\
\hline
\end{tabular}

\begin{tabular}{l|l|r}
14.7 & 22.8 & 62.6 \\
\hline
\end{tabular}
20.8
17.5
61.7

\begin{tabular}{l|l|l}
\hline 11.8 & 29.5 & 58.6 \\
\hline
\end{tabular}

\begin{tabular}{|l|l|l|}
\hline 19.1 & 22.7 & 58.2 \\
\hline \multicolumn{3}{|c|}{} \\
\hline 17.0 & 25.0 & 58.0 \\
\hline
\end{tabular}

\begin{tabular}{l|l|l}
22.1 & 24.1 & 53.8 \\
\hline
\end{tabular}

\begin{tabular}{|c|cc|cc|}
\hline & 23.9 & \multicolumn{2}{c|}{29.9} & 46.2 \\
\hline & & & \\
\hline & & & \\
\hline
\end{tabular}

\section{Less than Satisfied $\square$ Somewhat Satisfied $\square$ Very Satisfied}

Figure 2 Percentage of Veteran respondents less than satisfied, somewhat satisfied, and very satisfied with VA health care, by domain. Satisfaction with cost of care; physical aspects of the facility; the pharmacy; inpatient, specialist, and mental health care; pain management; and women's health were only assessed when applicable. $N$ indicates the number of valid survey responses to the satisfaction questions for each domain. Abbreviations: VAMC = Veterans Affairs Medical Center, CBOC = Community-Based Outpatient Clinic. 
diabetes) and vice versa (e.g., depression, PTSD), the total number of conditions did not differ by race/ethnicity or gender.

\section{Satisfaction with VA Health Care}

Among 1196 respondents to the overall satisfaction question, $565(47.2 \%)$ were very satisfied, 431 (36.0\%) somewhat satisfied, and $200(16.7 \%)$ less than satisfied with VA health care. Within each facility, a majority of respondents reported being somewhat or very satisfied with VA health care overall (Fig. 1).
Satisfaction with care varied across specific domains (Fig. 2). Most respondents (73.8-76.4\%) reported being very satisfied with cost of care, physical community-based outpatient facilities, and pharmacy services. Some respondents (20.8-23.9\%) reported being less than satisfied with mental health care, pain management, and access. For each domain, respondents were significantly less likely to report being somewhat or less than satisfied versus very satisfied with their VA care ( $p<0.01$ for each; Fig. 3 and Appendix 4).

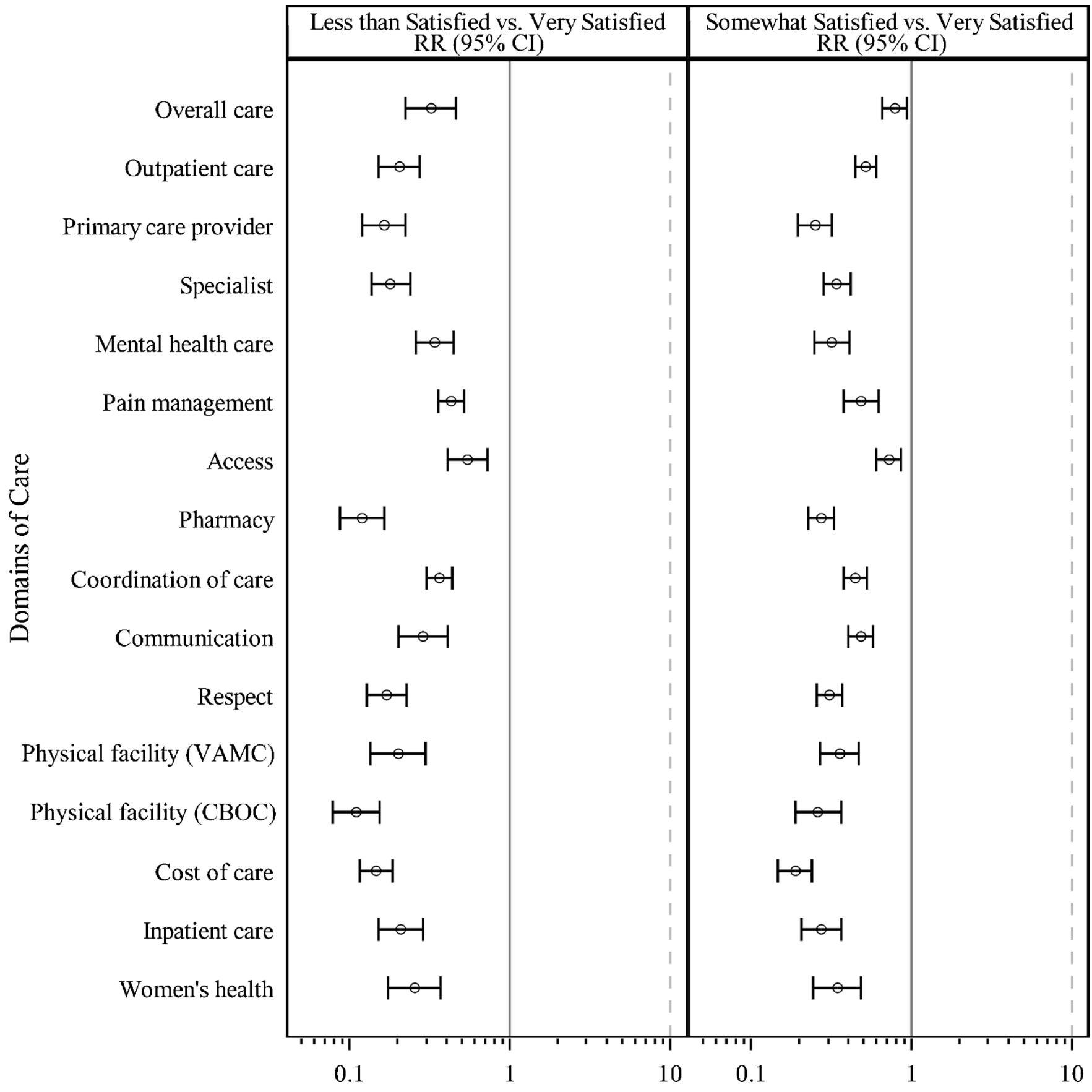

Figure 3 Domain-specific multinomial model comparisons of health care satisfaction for all Veteran respondents. Each set of two rate ratios (RRs) compares the probability of reporting being "less than satisfied" versus "very satisfied" (left entry) and the probability of reporting being "somewhat satisfied" versus "very satisfied" (right entry). RRs to the left of 1.0 favor "very satisfied". Abbreviations: VAMC = Veterans Affairs Medical Center, CBOC = Community-Based Outpatient Clinic. 


\section{Differences in Satisfaction by Race/Ethnicity and Gender}

No two-parameter Wald test of racial/ethnic or gender differences achieved statistical significance for overall satisfaction or other domains (Appendices 5, 6). However, pairwise comparisons showed some evidence of racial/ethnic differences in specific levels of satisfaction within three domains. In ageadjusted multinomial models, black men were less likely than white men to be less than (vs. very) satisfied with access (relative rate ratio $[R R R]=0.52,95 \% \mathrm{CI}=0.28-0.97$; Fig. 4 and Appendix 4). Hispanic men were more likely than white men to be somewhat (vs. very) satisfied with cost of care $(\mathrm{RRR}=2.75,95 \% \mathrm{CI}=1.13-6.72)$, and Hispanic women were less likely than white women to be somewhat (vs. very) satisfied with pharmacy services $(\mathrm{RRR}=0.49,95 \% \mathrm{CI}=0.25$ 0.97). Some CIs are wide because few Veterans reported being

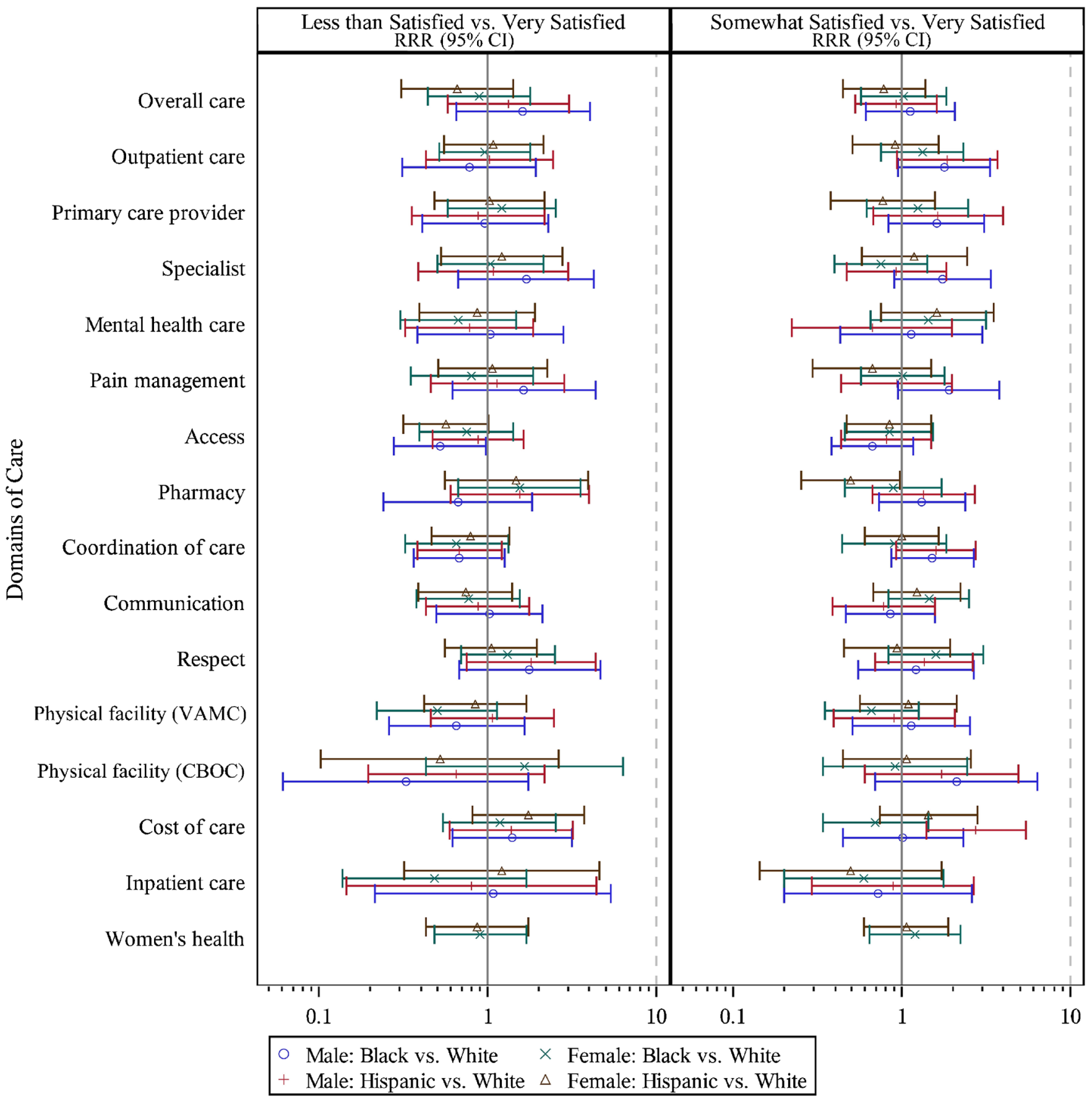

Figure 4 Gender-specific comparisons of health care satisfaction by race/ethnicity. The set of relative rate ratios (RRRs) for each domain compares the gender-specific RRs of reporting "less than satisfied" versus "very satisfied" (left entry) and the RRs of reporting being "somewhat satisfied" versus "very satisfied" (right entry). RRRs to the left of 1.0 favor black (or Hispanic) Veterans being "very satisfied" relative to white Veterans of the same gender. Abbreviations: VAMC = Veterans Affairs Medical Center, CBOC $=$ Community-Based Outpatient Clinic. 
less than satisfied and some domains pertained to relatively few respondents.

We identified some evidence of gender differences in levels of satisfaction by race/ethnicity in five domains. Black women were more likely than black men to be less than (vs. very) satisfied with pharmacy services $(\mathrm{RRR}=2.98,95 \% \mathrm{CI}=1.10$ 8.07; Fig. 5 and Appendix 6). White women were more likely than white men to be somewhat (vs. very) satisfied with outpatient care $(\mathrm{RRR}=2.00,95 \% \mathrm{CI}=1.08-3.70)$, cost of care
$(\mathrm{RRR}=2.46,95 \% \mathrm{CI}=1.13-5.38)$, and respect $(\mathrm{RRR}=2.52$, 95\% CI = 1.04-6.09). In contrast, black women were less likely than black men to be somewhat (vs. very) satisfied with specialist care $(\mathrm{RRR}=0.49,95 \% \mathrm{CI}=0.27-0.89)$.

These age-adjusted results were essentially unchanged in domain-specific models adjusting for additional demographic, clinical, and health care utilization characteristics, though some $p$-values changed slightly (Appendices 7, 8).

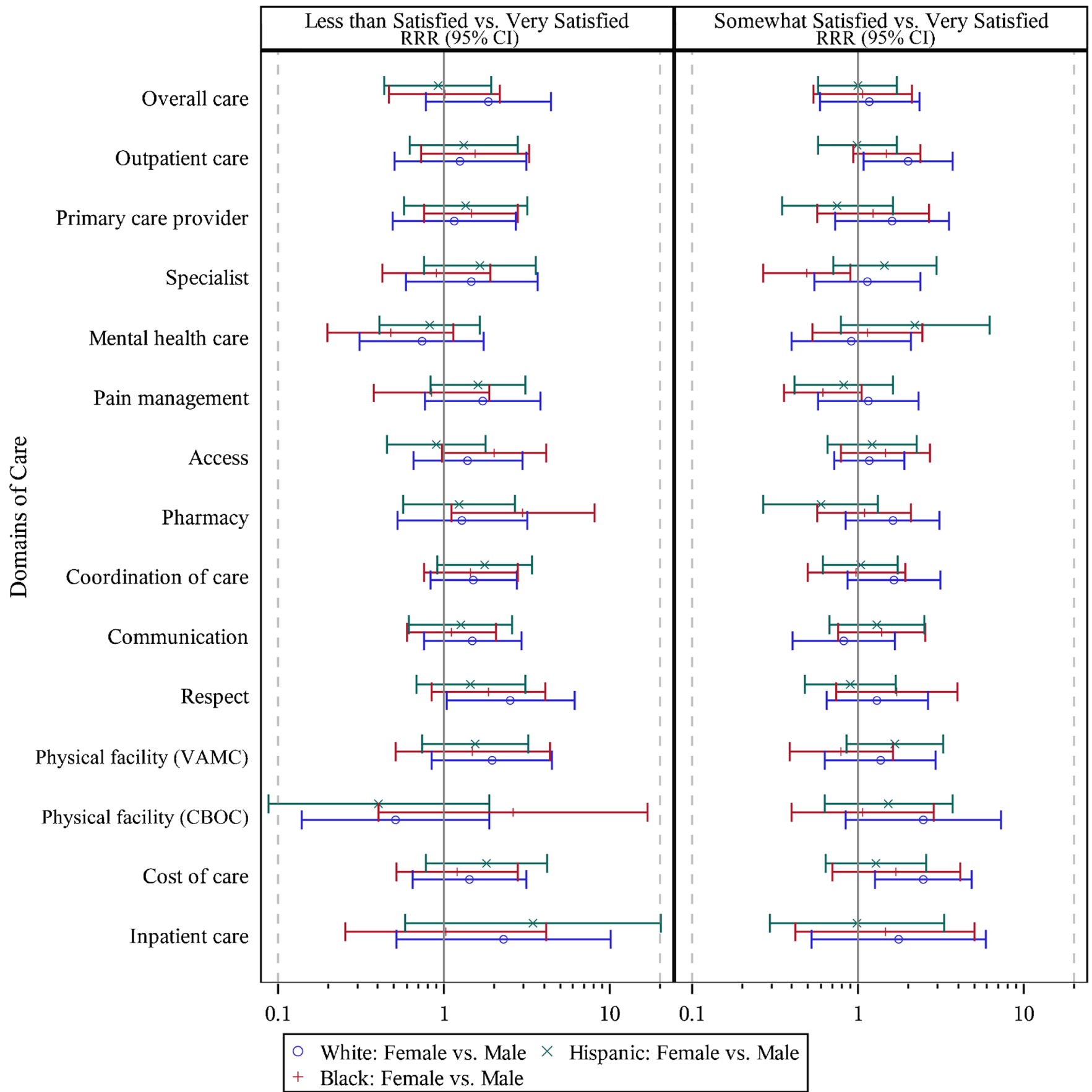

Figure 5 Race/ethnicity-specific comparisons of health care satisfaction by gender. The set of relative rate ratios (RRRs) for each domain compares the race/ethnicity-specific RRs of reporting "less than satisfied" versus "very satisfied" (left entry) and the RRs of reporting being "somewhat satisfied" versus "very satisfied" (right entry). RRRs to the left of 1.0 favor female Veterans being "very satisfied" relative to male Veterans of the same race/ethnicity. Abbreviations: VAMC = Veterans Affairs Medical Center, CBOC $=$ Community-Based Outpatient Clinic. 
A post hoc power calculation based on the observed sample sizes, intraclass correlation, and outcome distributions indicated that this study had $80 \%$ power to detect a gender-specific racial/ethnic difference of $17 \%$ in overall satisfaction (somewhat satisfied vs. very satisfied). A somewhat larger difference (25\%) could be detected for the less than satisfied vs. very satisfied comparisons.

\section{DISCUSSION}

Our interviews with Veterans from predominantly minorityserving VA Medical Centers across the US demonstrated that for all 16 domains assessed, respondents were more likely to be very satisfied with health care than somewhat or less than satisfied. Despite generally high levels of reported satisfaction overall, we identified some variation in satisfaction by domain. We found only a few pairwise differences in specific levels of satisfaction (i.e., less than or somewhat satisfied versus very satisfied) by race/ethnicity or gender, with no consistent direction of effect within demographic subgroups. Although several domains could be targeted for improvement efforts, our findings suggest that the VA is meeting generally its goal to ensure positive and equitable health care satisfaction among a growing population of minority Veterans.

Our finding that $83 \%$ of respondents were somewhat or very satisfied with VA health care overall is consistent with a recent Gallup survey, which found that $78 \%$ of patients receiving care through the VA or military insurance were satisfied with care. ${ }^{24}$ Ratings of satisfaction in the Gallup survey were higher for participants receiving VA or military health care than for participants receiving care through Medicaid (77\%), Medicare (75\%), employer-sponsored insurance $(69 \%)$, or individually purchased insurance $(65 \%)$. In the current study, more than $70 \%$ of respondents reported being very satisfied with care in 7 of the 16 domains assessed, with the highest satisfaction reported for the cost of care, physical aspects of facilities, and pharmacy. Our finding of relatively high satisfaction with costs and pharmacy might be explained by VA efforts to minimize cost sharing for Veterans. For example, enrollees pay no monthly premiums or enrollment fees, and copayments and prescription costs in the VA are reduced compared to those in other health care systems. ${ }^{25}$

Our examination of satisfaction across a comprehensive set of domains identified areas of lower satisfaction that could help inform VA efforts to improve health care delivery. More than $20 \%$ of respondents were less than satisfied with general pain management, mental health care, and access. Dissatisfaction with pain management and mental health care is of concern, because these disorders are highly prevalent in the $\mathrm{VA},{ }^{26,27}$ and satisfaction has been linked to improved clinical outcomes. ${ }^{28}$ Our finding of relatively low satisfaction with access is consistent with concerns prompting passage of the Veterans Access, Choice, and Accountability Act of 2014, ${ }^{29,30}$ which coincided with our study. As more Veterans receive care in the community following passage of the Veterans Choice Act, longitudinal evaluations of Veteran satisfaction with access to VA and non-VA providers will be important in determining the policy's success.

This study provides new insights into patient perceptions of care in VA facilities with relatively large concentrations of black and/or Hispanic patients. Contrary to prior studies, ${ }^{13}$ we identified little evidence of racial/ethnic disparities in health care satisfaction, with three exceptions. Our study provides some evidence that Hispanic men are less satisfied than white men with the cost of care, black men are more satisfied than white men with access to care, and Hispanic women are more satisfied than white women with pharmacy services. Previous national studies of racial/ethnic differences in experiences with VA health care found that a majority of blackwhite and Hispanic-white differences in health care experiences could be attributed to variations between facilities where blacks, whites, and Hispanics received care. ${ }^{7,12}$ Our finding of few racial/ethnic differences within VA facilities serving black and Hispanic patients supports previous results suggesting that efforts to improve health care satisfaction across racial/ethnic groups might begin by focusing on areas of dissatisfaction (e.g., access, mental health care) in those facilities where large numbers of black and Hispanic Veterans receive care. ${ }^{7}$

Our study also examined potential interactions between race/ethnicity and gender in predicting patient satisfaction. In contrast to previous studies, which found no gender differences $^{12}$ or found more positive experiences among female than male Veterans, ${ }^{12}$ the current study provides some evidence that white women (vs. men) experience less satisfaction with outpatient care, costs, and respect, and that black women (vs. men) are less satisfied with pharmacy services but more satisfied with specialist care. While the VA appears to be making the health care environment welcoming to both male and female Veterans, varying patterns of gender differences across racial/ethnic groups suggest that efforts to further ensure gender equity may need to be culturally targeted.

Our study has some limitations. First, it focused on withinfacility racial/ethnic and gender differences at primarily minority-serving facilities; results do not generalize to other VA facilities, and thus it is not possible to quantify the magnitude of between-facility differences in satisfaction by race/ ethnicity or gender on a national level. Second, our study respondents represent a stratified sample of eligible Veterans, and the demographic composition of the sample does not reflect that of the populations at participating sites. Furthermore, we observed a modest response rate and were unable to assess potential bias due to inability to contact for screening, decline of screening, or refusal of consent for the voice recording. Unwillingness to participate could be associated with satisfaction. Third, the study was powered to detect pairwise differences in overall satisfaction by race/ethnicity within gender, but has limited power to detect differences in domains that are applicable to smaller subsets of Veterans, such as inpatient care. These statistical analyses are considered 
descriptive rather than inferential, and provide the background for the ongoing qualitative analysis. Finally, given the large number of statistical comparisons performed, some positive associations would be expected simply by chance.

In summary, this large, multisite study demonstrated generally high levels of satisfaction with VA health care across several outpatient, inpatient, and specialist domains in primarily minority-serving VA medical centers. We also identified some domains where satisfaction could be improved for all Veterans managed in minority-serving facilities, and more specifically for Hispanic men, black women, and white women. Understanding differences in satisfaction across health care domains and how these differences vary by race/ethnicity and gender will enable the VA to improve health care experiences for the increasingly diverse population of US Veterans.

Acknowledgments: This work was supported by Department of Veterans Affairs Health Services Research and Development Merit Review (IIR 100144) and Service Directed Research (13-425) awards. The content of this article is solely the responsibility of the authors and does not necessarily represent the views of the Department of Veterans Affairs or the United States Government.

Corresponding Author: Susan L. Zickmund, $\mathrm{PhD}$; Informatics, Decision-Enhancement and Analytic Sciences Center (IDEAS 2.0)VA Salt Lake City Health Care System, Salt Lake City, UT, USA (e-mail: Susan.Zickmund@va.gov).

Compliance with Ethical Standards:

Conflict of Interest: All authors declare that they have no conflict of interest.

\section{REFERENCES}

1. Institute of Medicine Committee on Quality of Health Care in America Crossing the quality chasm: A new health system for the 21 st century. Washington (DC): National Academies Press; 2001.

2. Zickmund SL, Burkitt $\mathbf{K H}$, Gao $\mathbf{S}$, et al. Racial differences in satisfaction with VA health care: A mixed methods pilot study. J Racial Ethn Health Disparities. 2015;2(3):317-29.

3. Zolnierek KBH, Dimatteo MR. Physician communication and patient adherence to treatment: A meta-analysis. Med Care. 2009;47(8):826-34.

4. Anhang Price R, Elliott MN, Zaslavsky AM, et al. Examining the role of patient experience surveys in measuring health care quality. Med Care Res Rev. 2014;71(5):522-54.

5. Sequist TD, Schneider EC, Anastario M, et al. Quality monitoring of physicians: Linking patients' experiences of care to clinical quality and outcomes. J Gen Intern Med. 2008;23(11):1784-90.

6. Stanowski AC, Simpson K, White A. Pay for performance: Are hospitals becoming more efficient in improving their patient experience? J Healthc Manag. 2015;60(4):268-85.

7. Hausmann LR, Gao S, Mor MK, Schaefer JH, Jr., Fine MJ. Understanding racial and ethnic differences in patient experiences with outpatient health care in Veterans Affairs medical centers. Med Care. 2013;51(6):532-9.

8. Wright SM, Craig T, Campbell S, Schaefer J, Humble C. Patient satisfaction of female and male users of Veterans Health Administration services. J Gen Intern Med. 2006;21(Suppl 3):S26-32.
9. Department of Veterans Affairs. Veterans Health Administration Blueprint for Excellence. Washington DC: U.S. Department of Veterans Affairs; 2014

10. Wolf JA, Niederhauser V, Marshburn D, LaVela S. Defining patient experience. Patient Experience J. 2014;1(1):7-19.

11. Bleich SN, Ozaltin E, Murray CK. How does satisfaction with the healthcare system relate to patient experience? Bull World Health Organ. 2009;87(4):271-8.

12. Hausmann LRM, Gao S, Mor MK, Schaefer JHJ, Fine MJ. Patterns of sex and racial/ethnic differences in patient health care experiences in US Veterans Affairs hospitals. Med Care. 2014;52(4):328-35.

13. Jones AL, Mor MK, Cashy JC, et al. Racial/ethnic differences in primary care experiences in patient-centered medical homes among veterans with mental health and substance use disorders. J Gen Intern Med. 2016;31(12): 1345-1443.

14. Wright SM, Schaefer J, Reyes-Harvey E, Francis J. Comparing the care of men and women veterans in the Department of Veterans Affairs. Washington DC: Department of Veterans Affairs Office of Informatics \& Analytics; 2012.

15. Harada ND, Villa VM, Andersen R. Satisfaction with VA and non-VA outpatient care among veterans. Am J Med Qual. 2002;17(4):155-64.

16. Jones AL, Hanusa BH, Appelt CJ, Haas GL, Gordon AJ, Hausmann LR. Racial differences in veterans' satisfaction with addiction treatment services. J Addict Med. 2015;9(5):383-90.

17. Greenberg GA, Rosenheck RA. Changes in satisfaction with mental health services among blacks, whites, and Hispanics in the Department of Veterans Affairs. Psychiatr Q. 2004;75(4):375-89.

18. Kressin NR, Skinner $\mathbf{K}$, Sullivan $\mathbf{L}$, et al. Patient satisfaction with Department of Veterans Affairs health care: Do women differ from men? Mil Med. 1999;164(4):283-8.

19. Hall JA, Dornan MC. Patient sociodemographic characteristics as predictors of satisfaction with medical care: A meta-analysis. Soc Sci Med. 1990;30(7):811-8.

20. Chew LD, Griffin JM, Partin MR, et al. Validation of screening questions for limited health literacy in a large VA outpatient population. J Gen Intern Med. 2008;23(5):561-6.

21. Chaudhry S, Jin L, Meltzer D. Use of a self-report-generated Charlson Comorbidity Index for predicting mortality. Med Care. 2005;43(6):607-15

22. Hays RD, Sherbourne CD, Mazel RM. The RAND 36-Item Health Survey 1.0. Health Econ. 1993;2(3):217-27.

23. Ware JE, Jr., Sherbourne CD. The MOS 36-item short-form health survey (SF-36). I. Conceptual framework and item selection. Med Care. 1992;30(6):473-83.

24. Riffkin R. Americans with government health plans most satisfied. Health care. 6, 2015. http://news.gallup.com/poll/186527/americansgovernment-health-plans-satisfied.aspx. Accessed 14 Dec 2017.

25. Congressional Budget Office. Comparing the Costs of the Veterans' Health Care System with Private-Sector Costs. Congressional Budget Office; December 2014. https://www.cbo.gov/publication/49763. Accessed 13 Dec 2017.

26. Dobscha SK, Soleck GD, Dickinson KC, et al. Associations between race and ethnicity and treatment for chronic pain in the VA. J Pain. 2009;10(10):1078-87.

27. Seal KH, Bertenthal D, Miner CR, Sen S, Marmar C. Bringing the war back home: Mental health disorders among 103,788 US veterans returning from Iraq and Afghanistan seen at Department of Veterans Affairs facilities. Arch Intern Med. 2007; 167(5):476-4-82.

28. Deen TL, Fortney JC, Pyne JM. Relationship between satisfaction, patient-centered care, adherence and outcomes among patients in a collaborative care trial for depression. Adm Policy Ment Health. 2011;38(5):345-55.

29. U.S. Department of Veterans Affairs. Fact Sheet: Veterans Access, Choice, and Accountability Act 2014. VA Office of Public Affairs. https://www.va. gov/opa/choiceact/documents/Choice-Program-Fact-Sheet-Final.pdf. Accessed 13 Dec 2017.

30. Chokshi DA. Improving health care for veterans-a watershed moment for the VA. N Engl J Med. 2014;371(4):297-9. 
Appendix 1

Table 2 Facility location and distribution of race, ethnicity, and gender characteristics of outpatients from 25 participating VA medical centers. Facilities ordered by increasing percentage of White patients. The race/ethnicity columns do not add to $100 \%$ due to the exclusion of Veterans of other race or ethnicity and those with no documentation of race/ethnicity from numerators

\begin{tabular}{|c|c|c|c|c|c|}
\hline Site ID & $\overline{\text { State }}$ & $\begin{array}{l}\text { Percent } \\
\text { White }\end{array}$ & $\begin{array}{l}\text { Percent } \\
\text { Black }\end{array}$ & $\begin{array}{l}\text { Percent } \\
\text { Hispanic }\end{array}$ & $\overline{\text { Percent Female }}$ \\
\hline 1 & $\mathrm{DC}$ & 23.3 & 33.9 & 1.3 & 9.8 \\
\hline $\begin{array}{l}1 \\
2\end{array}$ & TX & 31.5 & 4.3 & 20.5 & $\begin{array}{l}7.0 \\
7.8\end{array}$ \\
\hline 3 & $\mathrm{NM}$ & 33.5 & 1.5 & 17.5 & 6.4 \\
\hline 4 & IL & 34.1 & 45.1 & 4.3 & 5.8 \\
\hline 5 & GA & 35.2 & 31.8 & 0.9 & 9.9 \\
\hline 6 & VA & 39.3 & 42.5 & 2.4 & 14.1 \\
\hline 7 & NY & 39.9 & 26.1 & 13.9 & 4.8 \\
\hline 8 & $\mathrm{AL}$ & 40.3 & 36.5 & 1.0 & 8.9 \\
\hline 9 & $\mathrm{CA}$ & 40.9 & 16.2 & 9.3 & 5.5 \\
\hline 10 & NY & 41.0 & 30.4 & 11.5 & 6.6 \\
\hline 11 & CA & 42.4 & 4.1 & 13.3 & 4.9 \\
\hline 12 & TX & 43.7 & 3.7 & 21.4 & 8.7 \\
\hline 13 & $\mathrm{CA}$ & 44.5 & 14.9 & 11.3 & 5.3 \\
\hline 14 & FL & 46.4 & 16.2 & 9.9 & 5.8 \\
\hline 15 & $\mathrm{NC}$ & 48.7 & 31.4 & 0.9 & 7.8 \\
\hline 16 & LA & 51.1 & 36.8 & 0.9 & 6.5 \\
\hline 17 & $\mathrm{CO}$ & 52.2 & 7.0 & 9.8 & 8.8 \\
\hline 18 & $\mathrm{CA}$ & 56.9 & 8.1 & 11.7 & 5.5 \\
\hline 19 & $\mathrm{CA}$ & 57.6 & 11.5 & 10.5 & 8.3 \\
\hline 20 & TX & 61.4 & 24.7 & 6.5 & 6.7 \\
\hline 21 & $\mathrm{AZ}$ & 62.4 & 4.0 & 9.4 & 7.7 \\
\hline 22 & $\mathrm{AZ}$ & 62.7 & 0.7 & 2.3 & 5.1 \\
\hline 23 & RI & 69.4 & 2.8 & 1.0 & 4.0 \\
\hline 24 & $\mathrm{CO}$ & 79.9 & 0.7 & 3.7 & 5.5 \\
\hline 25 & $\mathrm{NC}$ & 85.6 & 5.5 & 0.4 & 4.5 \\
\hline
\end{tabular}




\section{Appendix 2}

Quantitative and Qualitative Interview Items, by Domain of Care

\section{Overall VA Care}

For this first question, please think about your overall VA health care experience at [insert VA medical center/clinic].

How satisfied are you with your health care overall? Are you...(insert options)

$\square$ Very satisfied

$\square$ Somewhat satisfied

$\square$ Neither satisfied nor dissatisfied

$\square$ Somewhat dissatisfied

$\square$ Very dissatisfied

$\square$ Refused

$\square$ Not applicable

$\square$ Don't know

What contributed to your overall rating for your health care?

What could the VA do to improve your overall satisfaction with your health care?

Now, please think about your VA health care experience at [insert VA medical center/clinic] over the past 24 months.

Have you been more satisfied or less satisfied with your care in the last 24 months?

[If needed] Can you tell me what has changed during this time?

\section{Outpatient VA Care}

Now I'd like to ask about your outpatient VA clinic visits overall.

How satisfied are you with the care you have received during your outpatient clinic visits in general? Are you...(insert options)?

$\square$ Very satisfied

$\square$ Somewhat satisfied

$\square$ Neither satisfied nor dissatisfied

$\square$ Somewhat dissatisfied

$\square$ Very dissatisfied

$\square$ Refused

$\square$ Not applicable

$\square$ Don't know

What contributed to your overall rating for your outpatient clinic visits?

What could the VA do to improve your satisfaction with your outpatient clinic visits?

\section{Competence (Primary Care Provider)}

Now I'd like to ask you some questions about your primary care provider, or PCP, at the VA. This is the health care provider who manages your care and knows your health issues the best. It could be a doctor, a nurse practitioner, or a physician's assistant.

Do you have one person who you think of as your primary care provider, or PCP, at the VA?

$\square$ Yes

$\square$ No

$\square$ Don't Know

$\square$ Other:

$\square$ Refused

\section{IF NO: Go to Question 4 \\ IF DON'T KNOW: Go to Question 4 \\ IF OTHER: Continue (if applicable) or Go to Question 4 \\ IF REFUSED: Go to Question 4}

IF YES: Is your primary care provider, or PCP, located at [insert VA site] or at a different site (such as a clinic)?

$\square$ Main hospital

$\square$ Clinic (specify:

$\square$ Other:

$\square$ Refused

$\square$ Don't know

How satisfied are you with the health care provided by your PCP? Are you...(insert options)?

$\square$ Very satisfied

$\square$ Somewhat satisfied

$\square$ Neither satisfied nor dissatisfied

$\square$ Somewhat dissatisfied

$\square$ Very dissatisfied

$\square$ Refused

$\square$ Not applicable

$\square$ Don't know

What contributed to your rating for the health care provided by your PCP?

Please share how your provider and his/her medical staff discussed any barriers you may face in taking care of your health?

To what extend have they helped you to set health goals?

[If they have]: Have they helped you to achieve those goals?

What could the VA do to improve your satisfaction with the health care your PCP provides to you?

\section{Competence (Specialists)}

Next, I'd like to ask you some questions about health care from VA specialty providers. Specialists are doctors, nurse practitioners, or physician's assistants who provide health care in a focused area of medicine, such as heart disease, lung disease, diabetes, skin conditions, issues with your eyes or hearing, for example. 
Have you ever received care from a VA specialty provider?

$\square$ Yes

$\square$ No

$\square$ Don't know

IF NO: Go to Question 5

$\square$ Other:

IF DON'T KNOW: Go to Question 5

IF OTHER: Continue (if applicable) or Go to Question 5

What types of specialists have you received care from [check all that apply]:

$\square$ Allergy and Immunology (e.g., allergist and allergy staff for immunotherapy and diagnostic testing for seasonal, food, and other allergies)

$\square$ Cardiology Service (e.g., cardiologists for heart care and heart problems, including pacemakers and defibrillators)

$\square$ Dermatology (e.g., dermatologists dealing with the skin and its diseases)

$\square$ Diabetes and Endocrinology Service (e.g., endocrinologists or diabetes educators who provide treatment for diabetes and other hormone-related disorders)

$\square$ Eye Care (e.g., optometry or ophthalmology)

$\square$ Gastroenterology (e.g., GI, focuses on diseases affecting the GI tract and liver such as colorectal cancer screening, endoscopy, hepatitis B \& C, inflammatory bowel disease)

$\square$ Nephrology (e.g., nephrologists focus on diagnosis and treatment of Veterans with kidney diseases, including dialysis treatment)

$\square$ Neurology (e.g., neurologists focus on Multiple Sclerosis [MS], Parkinson's, Epilepsy, Amyotropic Lateral Sclerosis [ALS/Lou Gehrig's disease])

$\square$ Oncology \& Hematology (e.g., oncologists focus on detection, diagnosis and treatment of cancer)

$\square$ Podiatry (e.g., podiatrists focus on disorders of the foot, ankle and lower leg)

$\square$ Rheumatology (e.g., internal medicine subspecialty focused on clinical problems involving joints, soft tissues, and autoimmune diseases, such as, osteoarthritis or rheumatoid arthritis, osteoporosis, gout, and fibromyalgia)

$\square$ Surgery

$\square$ Urology (e.g., urologists focus on enlarged prostate, erectile dysfunction, etc.)

$\square$ Pain clinic

$\square$ Mental health

$\square$ Don't know

$\square$ Refused

$\square$ Other:

DO NOT COUNT THE FOLLOWING AS SPECIALISTS:

- Radiology techs

- Lab techs/phlebotomists

- Anesthesia services

- Chaplain services

- Critical Care

- VA DOD Vision Center of Excellence

- Genomic medicine service

- National infectious disease service

- Nutrition and food service

- Specialty care transformation

IF YES: How satisfied are you with the health care provided by your specialist(s)? Are you...(insert options)?

$\square$ Very satisfied

$\square$ Somewhat satisfied

$\square$ Neither satisfied nor dissatisfied

$\square$ Somewhat dissatisfied

$\square$ Very dissatisfied

$\square$ Refused

$\square$ Not applicable

$\square$ Don't know

What contributed to your rating for the care provided by your specialist(s)?

- REQUIRED PROMPTS (IF MULTIPLE SPECIALISTS MENTIONED): What kind of specialist(s) were involved in the experiences you provided to support your satisfaction rating?

What could the VA do to improve your satisfaction with the health care your specialist(s) provide to you?

\section{Mental Health}

Next, I'd like to ask you about VA mental health services. Mental health is another type of specialty service provided by the VA. A mental health provider may be a social worker, a psychologist, a psychiatrist, or some other type of provider who assists you with issues regarding things such as nervousness, feeling down, trauma experiences, drinking or using drugs, or coping with life stress.

Have you ever received mental health care services?

$\square$ Yes

$\square$ No

$\square$ Don't know

$\square$ Refused

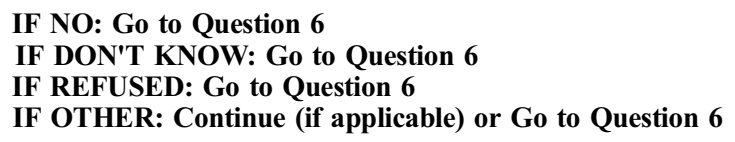
IF OTHER: Continue (if applicable) or Go to Question 6

$\square$ Other:

IF YES: Have you received mental health services from a specialist (such as a psychologist, psychiatrist, or social worker), your primary care physician, or both?

$\square$ Specialist

$\square$ PCP

$\square$ Both

$\square$ Don't know 
$\square$ Refused

$\square$ Other (specify:

How satisfied are you with the mental health services you received? Are you...(insert options)?

$\square$ Very satisfied

$\square$ Somewhat satisfied

$\square$ Neither satisfied nor dissatisfied

$\square$ Somewhat dissatisfied

$\square$ Very dissatisfied

$\square$ Refused

$\square$ Not applicable

$\square$ Don't know

What contributed to your rating for the mental health services you received?

\section{REQUIRED PROMPTS:}

- Are you satisfied with your ability to get mental health services?

What could the VA do to improve your satisfaction with the mental health services you received?

\section{Pain Management}

Next, I'd like to ask you about how your VA health care providers may have helped manage your pain.

Have you ever received treatment for any type of pain?

$\square$ Yes

$\square$ No

$\square$ Don't know

$\square$ Refused

IF NO: Go to Question 7.

$\square$ Other :

IF DON'T KNOW: Go to Question 7

IF REFUSED: Go to Question 7

IF YES: Did you receive treatment for your pain from your PCP or a specialist?

$\square$ PCP

$\square$ Specialist

What types of specialists have you received pain management from [check all that apply]:

$\square$ Pain clinic

$\square$ Neurology (e.g., neurologists focus on MS, Parkinson's, Epilepsy, Amyotropic Lateral Sclerosis [ALS/Lou Gehrig's disease])

$\square$ Podiatry (e.g., podiatrists focus on disorders of the foot, ankle and lower leg)

$\square$ Rheumatology (e.g., internal medicine subspecialty focused on clinical problems involving joints, soft tissues, and autoimmune diseases, such as, osteoarthritis or rheumatoid arthritis, osteoporosis, gout, and fibromyalgia)

$\square$ Don’t know

$\square$ Refused

$\square$ Other:

$\square$ Both

\section{REQUIRED PROMPTS :}

- What kind(s) of pain have you received treatment for?

- Was your pain a long-standing issue or was it due to a short illness or injury?

- How often have you received pain management treatment?

IF YES: How satisfied are you with the way your pain was managed? Are you...(insert options)?

$\square$ Very satisfied

$\square$ Somewhat satisfied

$\square$ Neither satisfied nor dissatisfied

$\square$ Somewhat dissatisfied

$\square$ Very dissatisfied

$\square$ Refused

$\square$ Not applicable

$\square$ Don't know

What contributed to your rating for how your pain was managed?

\section{REQUIRED PROMPTS:}

- Are you satisfied with your ability to get pain management?

What could the VA do to improve your satisfaction with your pain management?

\section{Access (General)}

Next, I will ask you a few questions about your ability to get health care at the VA.

How satisfied are you with your ability to get the medical care you need when you need it? Are you...(insert options)?

$\square$ Very satisfied

$\square$ Somewhat satisfied

$\square$ Neither satisfied nor dissatisfied

$\square$ Somewhat dissatisfied

$\square$ Very dissatisfied

$\square$ Refused

$\square$ Not applicable

$\square$ Don't know

What contributed to your rating for your ability to get health care when you need it? 


\section{REQUIRED PROMPTS:}

- Are you satisfied with the process used to schedule appointments?

- Are you satisfied with your ability to schedule appointments when you need them?

- Are you satisfied with how long you wait to see your health care provider when you arrive for a scheduled appointment?

- Are you satisfied with the process involved in having lab work completed or imaging tests completed, such as X-ray, CAT scan, or MRI?

- Are you satisfied with the required forms, policies, and procedures that must be completed in order to receive at the VA?

- Have you ever had to use the emergency room (ER) because you were unable to schedule an appointment when you needed one?

- Have you ever sought care outside of the VA for services that you could have received within the VA health care system?

What could the VA do to help improve your satisfaction with your ability to get health care when you need it?

\section{Pharmacy}

Next, I'd like to ask you about the VA pharmacy to get prescription medication.

Have you used the VA pharmacy services to get medication? (Check one.)

$\square$ Yes

$\square$ No

$\square$ Don't know

IF NO: Go to Question 9.

$\square$ Refused

IF DON'T KNOW: Go to Question 9

$\square$ Other:

IF REFUSED: Go to Question 9

IF OTHER: Continue (if applicable) or Go to Question 9

IF YES: How do (or did) you usually request that your prescriptions be filled (check all that apply)?

$\square$ Directly at pharmacy services in the VA

$\square$ Mail

$\square$ Internet (My Health eVet)

$\square$ Telephone

$\square$ Don't know

$\square$ Refused

$\square$ Other:

IF YES: How do (or did) you usually receive your prescriptions (check all that apply)?

$\square$ Pick-up at VA

$\square$ Mail

$\square$ Don't know

$\square$ Refused

$\square$ Other:

IF YES: How satisfied are you with the pharmacy services? Are you...(insert options)?

$\square$ Very satisfied

$\square$ Somewhat satisfied

$\square$ Neither satisfied nor dissatisfied

$\square$ Somewhat dissatisfied

$\square$ Very dissatisfied

$\square$ Refused

$\square$ Not applicable

$\square$ Don't know

What contributed to your rating for the VA pharmacy services?

What could the VA do to improve your satisfaction with the VA pharmacy services?

\section{Continuity of Care}

Next, I'd like to ask you about how your various health care providers coordinate your overall health care.

How satisfied are you with how well your various health care providers coordinate your overall health care? Are you...(insert options)?

$\square$ Very satisfied

$\square$ Somewhat satisfied

$\square$ Neither satisfied nor dissatisfied

$\square$ Somewhat dissatisfied

$\square$ Very dissatisfied

$\square$ Refused

$\square$ Not applicable

$\square$ Don't know

What contributed to your rating for how well your various health care providers coordinate your overall health care?

What could the VA do to improve your satisfaction with how well your various health care providers coordinate your overall health care?

\section{Communication}

Next, I'd like to ask you about your communication with your health care providers.

How satisfied are you with your communication with your health care providers? Are you...(insert options)?

$\square$ Very satisfied

$\square$ Somewhat satisfied

$\square$ Neither satisfied nor dissatisfied

$\square$ Somewhat dissatisfied

$\square$ Very dissatisfied

$\square$ Refused

$\square$ Not applicable

$\square$ Don't know

What contributed to your rating for your communication with your health care providers? 


\section{REQUIRED PROMPTS:}

- Are you satisfied with the health care information you have gotten from your providers?

- Are you satisfied with how your health care providers have listened to you?

- Are you satisfied with how your health care providers have involved you in decisions about your health care?

What could the VA do to improve your satisfaction with your communication with your health care providers?

\section{Humaneness (Respect)}

Next, I'd like to ask you about the way you are treated in the VA by all health care providers, staff, and other personnel.

How satisfied are you with the level of respect, including compassion, kindness, and courtesy, you've been shown? Are you...(insert options)?

$\square$ Very satisfied

$\square$ Somewhat satisfied

$\square$ Neither satisfied nor dissatisfied

$\square$ Somewhat dissatisfied

$\square$ Very dissatisfied

$\square$ Refused

$\square$ Not applicable

$\square$ Don't know

What contributed to your rating for the respect you've been shown by all VA health care providers, staff, and other personnel?

What could the VA do to improve your satisfaction with the respect you've been shown by all VA health care providers, staff, and other personnel?

\section{Physical Facilities ("Parent" Site)}

Next, I'd like to ask you about the buildings and grounds at your VA facility.

How satisfied are you with the [insert VA facility] facility? Are you...(insert options)?

$\square$ Very satisfied

$\square$ Somewhat satisfied

$\square$ Neither satisfied nor dissatisfied

$\square$ Somewhat dissatisfied

$\square$ Very dissatisfied

$\square$ Refused

$\square$ Not applicable

$\square$ Don't know

What contributed to your rating for the [insert VA facility] facility?

\section{REQUIRED PROMPTS:}

- Are you satisfied with the level of cleanliness at the [insert VA facility] facility?

- Are you satisfied with the level of safety at the [insert VA facility] facility?

What could the VA do to improve your satisfaction with the [insert VA facility] facility?

\section{Physical Facilities (Clinic/Substation)}

Next, I'd like to ask you about the buildings and grounds at your VA clinic.

How satisfied are you with the [insert VA clinic] facility? Are you...(insert options)?

$\square$ Very satisfied

$\square$ Somewhat satisfied

$\square$ Neither satisfied nor dissatisfied

$\square$ Somewhat dissatisfied

$\square$ Very dissatisfied

$\square$ Refused

$\square$ Not applicable

$\square$ Don't know

What contributed to your satisfaction or dissatisfaction with the [insert VA clinic] facility?

\section{REQUIRED PROMPTS:}

- Are you satisfied with the level of safety at the [insert VA clinic] facility?

What could the VA do to improve your satisfaction with the [insert VA clinic] facility?

\section{Cost}

Next, I'd like to ask you about the cost you personally pay for your VA health care.

Do you have any costs you have to pay to get VA health care?

$\square$ Yes

$\square$ No

$\square$ Don't know

IF YES: Answer \#1, \#2, \#3, (below)

$\square$ Refused

IF NO: Answer \#2, \#3 (below)

$\square$ Other:

IF DON'T KNOW: Answer \#1, \#2, \#3 (below)

IF REFUSED: Answer \#1, \#2, \#3 (below)

IF OTHER: Answer \#1, \#2, \#3 (below)

How satisfied are you with the overall cost you personally pay for your VA health care? Are you...(insert options)?

$\square$ Very satisfied

$\square$ Somewhat satisfied

$\square$ Neither satisfied nor dissatisfied

$\square$ Somewhat dissatisfied 
$\square$ Very dissatisfied

$\square$ Refused

$\square$ Not applicable

$\square$ Don't know

What contributed to your rating for the cost you personally pay for your VA health care?

1. Is there any care that you chose not to receive from the VA because of the cost?

2. Would you still use the VA for health care if you had another option that cost the same amount?

3. Have you signed up for non-VA insurance made available by the Affordable Care Act (which some people call Obamacare)?

If yes: Can you explain why you made the change?

If no: Do you think you might sign-up for non-VA insurance through the Affordable Care Act in the future?

If yes: Can you explain why you may make this change in the future?

If no: Why do you choose to stay within the VA?

What could the VA do to improve your satisfaction with the cost you personally pay for your care?

\section{Inpatient VA Care}

Were you ever hospitalized overnight at the [insert VA site]?

$\square$ Yes

$\square$ No

$\square$ Don't Know

IF NO: Go to Closing

$\square$ Don't Know
$\square$ Refused

IF DON'T KNOW: Go to Closing

$\square$ Other:

\section{IF OTHER: Continue (if applicable) or Go to Closing}

How satisfied are you with the health care that you received during your overnight stay(s) at [insert VA site]? Are you...(insert options)?

$\square$ Very satisfied

$\square$ Somewhat satisfied

$\square$ Neither satisfied nor dissatisfied

$\square$ Somewhat dissatisfied

$\square$ Very dissatisfied

$\square$ Refused

$\square$ Not applicable

$\square$ Don't know

What contributed to your rating for the health care you received during your hospital stay(s)?

What could the VA do to improve your satisfaction with the health care you received during your hospital stay(s)?

\section{IF MALE or FEMALE $\square$ MALE TRANSGENDER PARTICIPANT: Go to DEMOGRAPHIC/HEALTH STATUS QUESTIONS}

IF FEMALE or MALE $\square$ FEMALE TRANSGENDER PARTICIPANT: Go to Question 17.

\section{Women's Health}

Now, I'd like to ask you about the care the VA has provided to you as a woman.

How satisfied are you with the care the VA has provided to you as a woman? Are you...(insert options)?

$\square$ Very satisfied

$\square$ Somewhat satisfied

$\square$ Neither satisfied nor dissatisfied

$\square$ Somewhat dissatisfied

$\square$ Very dissatisfied

$\square$ Refused

$\square$ Not applicable

$\square$ Don't know

What contributed to rating for the care the VA has provided to you as a woman?

\section{REQUIRED PROMPTS:}

In general throughout all of your experiences in the VA, how satisfied are you with how welcoming it has been to women?

- Are you satisfied with the amount of privacy you've experienced as a woman in the VA?

- Are you satisfied with your ability to easily get women's health care services (such as gynecologic services, mammography, pregnancy/obstetric care, etc.)?

- Are there any other things about your satisfaction or dissatisfaction with women's health care at the VA that you think we should know about?

What could the VA do to improve your satisfaction with the care the VA has provided to you as a woman?

\section{Closing}

We are almost done with the interview portion. We would now like to have you think more broadly about Veterans in general.

What is the main thing that Veterans are likely to be satisfied with related to their VA health care?

What is the main thing that Veterans are likely to be dissatisfaction with related to their VA health care?

What is the one thing the VA could do to improve Veterans' satisfaction with care?

In general, do you think being a woman in the VA affects the quality of care given to them?

Do you think a person's race or ethnicity affects the quality of care given to them?

Finally, do you think a person's sexual orientation affects the quality of care given to them?

Thanks so much for those answers. Are there any other things about your experience with receiving health care at the VA that you think we should know about? 


\section{Appendix 3}

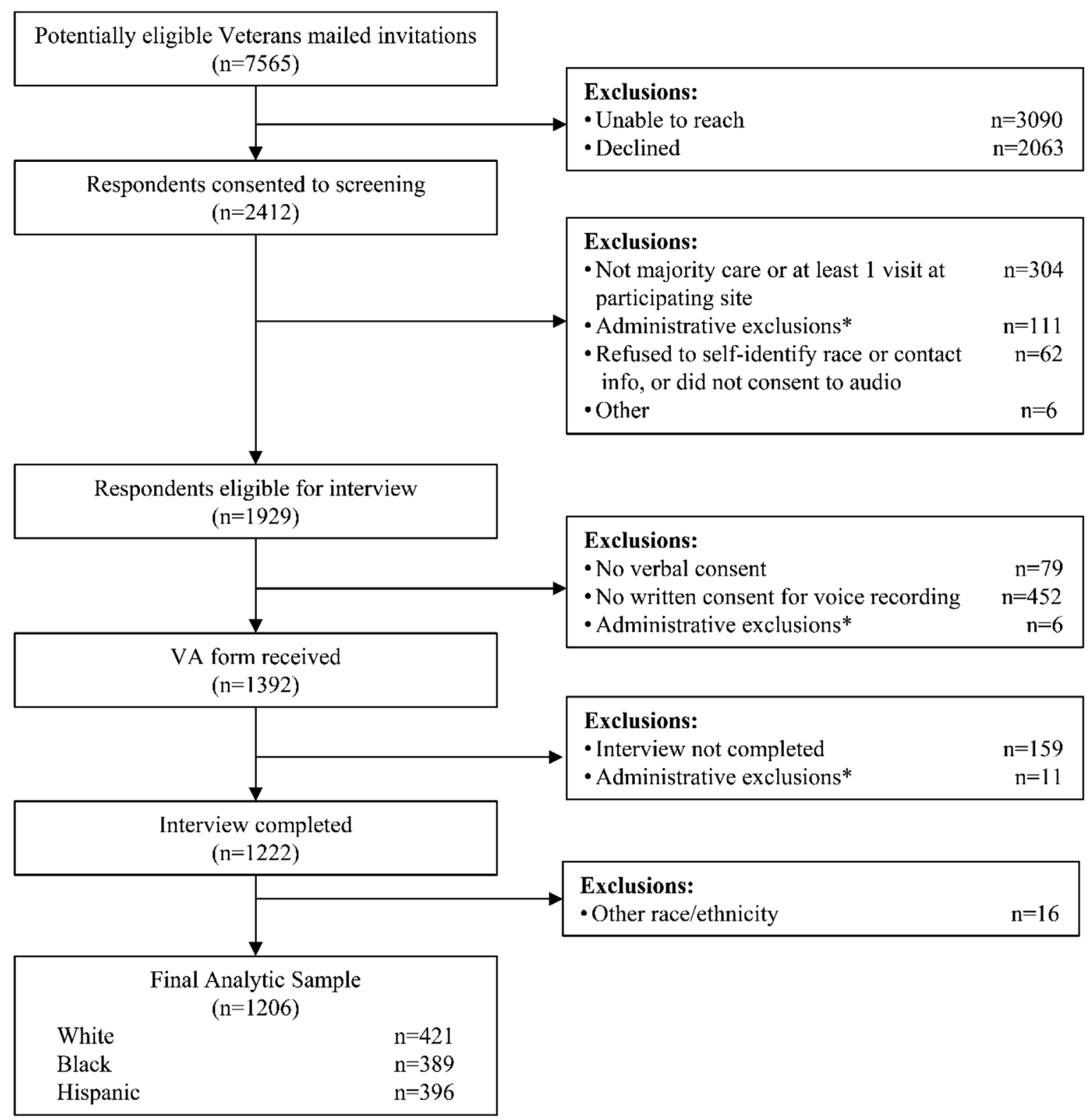

Figure 6 Participant recruitment and study enrollment, with exclusion criteria applied sequentially. The predominant reason for administrative exclusion was that a recruitment cell was filled by the time a potential respondent worked their way through the multi-step recruitment process. 
Appendix 4

Table 3 Age-adjusted Rate Ratios (RRs) and 95\% Confidence Intervals (CIs) comparing satisfaction with 16 domains of VA health care across all respondents. For each domain, rate ratios (RRs) and 95\% confidence intervals (CIs) were estimated from a mixed-effects multinomial regression model of health care satisfaction that included a random effect for VA facility and fixed effect for age

\begin{tabular}{|c|c|c|c|c|c|c|c|}
\hline \multirow[t]{2}{*}{ Domain of Health Care } & \multirow{2}{*}{$\frac{\text { Overall }}{P \text { Value }}$} & \multicolumn{3}{|c|}{ Less than Satisfied vs. Very Satisfied } & \multicolumn{3}{|c|}{ Somewhat Satisfied vs. Very Satisfied } \\
\hline & & $\mathbf{R R}$ & $95 \% \mathrm{CI}$ & $P$ Value & $\mathbf{R R}$ & $95 \% \mathrm{CI}$ & $P$ Value \\
\hline Overall care & $<.01$ & 0.32 & $0.22,0.46$ & $<.01$ & 0.78 & $0.66,0.93$ & 0.01 \\
\hline Outpatient care & $<.01$ & 0.20 & $0.15,0.28$ & $<.01$ & 0.52 & $0.45,0.60$ & $<.01$ \\
\hline Primary care provider & $<.01$ & 0.16 & $0.12,0.23$ & $<.01$ & 0.25 & $0.20,0.32$ & $<.01$ \\
\hline Specialist & $<.01$ & 0.18 & $0.14,0.24$ & $<.01$ & 0.34 & $0.28,0.41$ & $<.01$ \\
\hline Mental health care & $<.01$ & 0.34 & $0.26,0.44$ & $<.01$ & 0.32 & $0.25,0.41$ & $<.01$ \\
\hline Pain management & $<.01$ & 0.43 & $0.36,0.52$ & $<.01$ & 0.49 & $0.38,0.62$ & $<.01$ \\
\hline Access & $<.01$ & 0.55 & $0.41,0.73$ & $<.01$ & 0.72 & $0.60,0.86$ & $<.01$ \\
\hline Pharmacy & $<.01$ & 0.12 & $0.09,0.17$ & $<.01$ & 0.27 & $0.23,0.33$ & $<.01$ \\
\hline Coordination of care & $<.01$ & 0.37 & $0.30,0.44$ & $<.01$ & 0.44 & $0.37,0.53$ & $<.01$ \\
\hline Communication & $<.01$ & 0.29 & $0.20,0.41$ & $<.01$ & 0.48 & $0.40,0.57$ & $<.01$ \\
\hline Respect & $<.01$ & 0.17 & $0.13,0.23$ & $<.01$ & 0.31 & $0.26,0.37$ & $<.01$ \\
\hline Physical facility (VAMC) & $<.01$ & 0.20 & $0.14,0.30$ & $<.01$ & 0.36 & $0.27,0.47$ & $<.01$ \\
\hline Physical facility (CBOC) & $<.01$ & 0.11 & $0.08,0.15$ & $<.01$ & 0.26 & $0.19,0.36$ & $<.01$ \\
\hline Cost of care & $<.01$ & 0.15 & $0.12,0.19$ & $<.01$ & 0.19 & $0.15,0.24$ & $<.01$ \\
\hline Inpatient care & $<.01$ & 0.21 & $0.15,0.29$ & $<.01$ & 0.27 & $0.21,0.36$ & $<.01$ \\
\hline Women's health & $<.01$ & 0.25 & $0.17,0.37$ & $<.01$ & 0.34 & $0.24,0.49$ & $<.01$ \\
\hline
\end{tabular}

Abbreviations: $V A M C=$ Veterans Affairs Medical Center, $C B O C=$ Community-Based Outpatient Clinic 
Appendix 5

Table 4 Gender-specific comparisons of health care satisfaction by race/ethnicity. The set of Relative Rate Ratios (RRRs) for each domain compare the gender-specific RRs of reporting "less than satisfied" versus "very satisfied" (left entry) and the RRs of reporting being "somewhat satisfied" versus "very satisfied" (right entry). RRRs to the left of 1.0 favor Black (or Hispanic) Veterans being "very satisfied" relative to White Veterans of the same gender

\begin{tabular}{|c|c|c|c|c|c|c|c|}
\hline \multirow[t]{2}{*}{ Domain of Health Care (Gender) } & \multirow{2}{*}{ 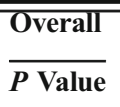 } & \multicolumn{3}{|c|}{ Less than Satisfied vs. Very Satisfied } & \multicolumn{3}{|c|}{ Somewhat Satisfied vs. Very Satisfied } \\
\hline & & $\overline{\mathbf{R R R}}$ & $95 \% \mathrm{CI}$ & $P$ Value & $\overline{\mathbf{R R R}}$ & $95 \% \mathrm{CI}$ & $P$ Value \\
\hline \multicolumn{8}{|l|}{ Overall care } \\
\hline Black vs. White (M) & 0.59 & 1.62 & $0.65,4.03$ & 0.30 & 1.12 & $0.61,2.05$ & 0.71 \\
\hline Hispanic vs. White (M) & 0.71 & 1.32 & $0.58,3.02$ & 0.51 & 0.92 & $0.53,1.62$ & 0.78 \\
\hline Black vs. White (F) & 0.90 & 0.89 & $0.44,1.79$ & 0.74 & 1.02 & $0.57,1.83$ & 0.95 \\
\hline Hispanic vs. White $(\mathrm{F})$ & 0.51 & 0.66 & $0.31,1.41$ & 0.28 & 0.78 & $0.45,1.37$ & 0.40 \\
\hline \multicolumn{8}{|l|}{ Outpatient care } \\
\hline Black vs. White (M) & 0.16 & 0.78 & $0.31,1.93$ & 0.59 & 1.78 & $0.95,3.33$ & 0.07 \\
\hline Hispanic vs. White (M) & 0.21 & 1.02 & $0.43,2.45$ & 0.96 & 1.85 & $0.93,3.69$ & 0.08 \\
\hline Black vs. White $(F)$ & 0.54 & 0.96 & $0.51,1.80$ & 0.90 & 1.32 & $0.75,2.32$ & 0.33 \\
\hline Hispanic vs. White (F) & 0.90 & 1.08 & $0.55,2.13$ & 0.82 & 0.92 & $0.51,1.66$ & 0.77 \\
\hline \multicolumn{8}{|l|}{ Primary care provider } \\
\hline Black vs. White (M) & 0.36 & 0.96 & $0.41,2.28$ & 0.93 & 1.60 & $0.83,3.07$ & 0.16 \\
\hline Hispanic vs. White (M) & 0.53 & 0.87 & $0.35,2.16$ & 0.77 & 1.64 & $0.67,3.99$ & 0.28 \\
\hline Black vs. White (F) & 0.74 & 1.21 & $0.58,2.54$ & 0.61 & 1.24 & $0.62,2.47$ & 0.55 \\
\hline Hispanic vs. White (F) & 0.76 & 1.02 & $0.48,2.17$ & 0.96 & 0.77 & $0.38,1.57$ & 0.47 \\
\hline \multicolumn{8}{|l|}{ Specialist } \\
\hline Black vs. White (M) & 0.18 & 1.69 & $0.67,4.25$ & 0.27 & 1.74 & $0.90,3.36$ & 0.10 \\
\hline Hispanic vs. White (M) & 0.95 & 1.08 & $0.39,3.02$ & 0.88 & 0.93 & $0.47,1.83$ & 0.83 \\
\hline Black vs. White $(F)$ & 0.63 & 1.03 & $0.50,2.13$ & 0.93 & 0.75 & $0.40,1.41$ & 0.37 \\
\hline Hispanic vs. White $(\mathrm{F})$ & 0.84 & 1.21 & $0.53,2.79$ & 0.65 & 1.18 & $0.58,2.42$ & 0.65 \\
\hline \multicolumn{8}{|l|}{ Mental health care } \\
\hline Black vs. White (M) & 0.97 & 1.03 & $0.38,2.79$ & 0.95 & 1.14 & $0.43,3.01$ & 0.80 \\
\hline Hispanic vs. White (M) & 0.71 & 0.78 & $0.32,1.85$ & 0.57 & 0.66 & $0.22,1.97$ & 0.46 \\
\hline Black vs. White (F) & 0.28 & 0.67 & $0.30,1.48$ & 0.32 & 1.43 & $0.65,3.14$ & 0.37 \\
\hline Hispanic vs. White $(\mathrm{F})$ & 0.40 & 0.86 & $0.39,1.91$ & 0.72 & 1.62 & $0.75,3.49$ & 0.22 \\
\hline \multicolumn{8}{|l|}{ Pain management } \\
\hline Black vs. White (M) & 0.17 & 1.64 & $0.61,4.37$ & 0.32 & 1.90 & $0.95,3.80$ & 0.07 \\
\hline Hispanic vs. White (M) & 0.93 & 1.14 & $0.46,2.85$ & 0.78 & 0.93 & $0.44,1.99$ & 0.86 \\
\hline Black vs. White $(\mathrm{F})$ & 0.88 & 0.80 & $0.35,1.85$ & 0.61 & 1.01 & $0.57,1.78$ & 0.98 \\
\hline Hispanic vs. White (F) & 0.52 & 1.07 & $0.51,2.25$ & 0.86 & 0.66 & $0.29,1.49$ & 0.32 \\
\hline \multicolumn{8}{|l|}{ Access } \\
\hline Black vs. White (M) & 0.07 & 0.52 & $0.28,0.97$ & 0.04 & 0.67 & $0.38,1.17$ & 0.16 \\
\hline Hispanic vs. White (M) & 0.78 & 0.87 & $0.47,1.62$ & 0.66 & 0.81 & $0.44,1.49$ & 0.49 \\
\hline Black vs. White (F) & 0.67 & 0.75 & $0.39,1.42$ & 0.37 & 0.84 & $0.46,1.53$ & 0.57 \\
\hline Hispanic vs. White (F) & 0.15 & 0.56 & $0.31,1.01$ & 0.05 & 0.84 & $0.47,1.49$ & 0.55 \\
\hline \multicolumn{8}{|l|}{ Pharmacy } \\
\hline Black vs. White (M) & 0.45 & 0.66 & $0.24,1.84$ & 0.43 & 1.32 & $0.73,2.36$ & 0.36 \\
\hline Hispanic vs. White (M) & 0.54 & 1.54 & $0.60,3.97$ & 0.37 & 1.34 & $0.66,2.71$ & 0.41 \\
\hline Black vs. White $(\mathrm{F})$ & 0.47 & 1.54 & $0.66,3.57$ & 0.31 & 0.89 & $0.46,1.72$ & 0.72 \\
\hline Hispanic vs. White (F) & 0.06 & 1.48 & $0.56,3.93$ & 0.43 & 0.49 & $0.25,0.97$ & 0.04 \\
\hline Coordination of care & & & & & & & \\
\hline Black vs. White (M) & 0.12 & 0.68 & $0.36,1.26$ & 0.22 & 1.51 & $0.86,2.65$ & 0.15 \\
\hline Hispanic vs. White (M) & 0.09 & 0.68 & $0.38,1.21$ & 0.19 & 1.59 & $0.93,2.72$ & 0.09 \\
\hline Black vs. White (F) & 0.44 & 0.65 & $0.32,1.32$ & 0.24 & 0.90 & $0.44,1.83$ & 0.77 \\
\hline Hispanic vs. White $(\mathrm{F})$ & 0.65 & 0.79 & $0.47,1.35$ & 0.39 & 1.00 & $0.60,1.66$ & 1.00 \\
\hline Communication & & & & & & & \\
\hline Black vs. White (M) & 0.85 & 1.02 & $0.50,2.12$ & 0.95 & 0.85 & $0.46,1.55$ & 0.60 \\
\hline Hispanic vs. White (M) & 0.75 & 0.87 & $0.43,1.76$ & 0.69 & 0.77 & $0.38,1.55$ & 0.47 \\
\hline Black vs. White $(\mathrm{F})$ & 0.24 & 0.77 & $0.38,1.54$ & 0.45 & 1.44 & $0.83,2.51$ & 0.19 \\
\hline Hispanic vs. White (F) & 0.38 & 0.74 & $0.39,1.39$ & 0.35 & 1.23 & $0.68,2.23$ & 0.49 \\
\hline Respect & & & & & & & \\
\hline Black vs. White (M) & 0.50 & 1.77 & $0.67,4.66$ & 0.24 & 1.21 & $0.55,2.68$ & 0.63 \\
\hline Hispanic vs. White (M) & 0.31 & 1.81 & $0.75,4.38$ & 0.19 & 1.36 & $0.69,2.65$ & 0.37 \\
\hline Black vs. White (F) & 0.37 & 1.31 & $0.69,2.49$ & 0.41 & 1.59 & $0.83,3.04$ & 0.16 \\
\hline Hispanic vs. White $(\mathrm{F})$ & 0.96 & 1.04 & $0.55,1.96$ & 0.90 & 0.94 & $0.45,1.94$ & 0.86 \\
\hline Physical facility (VAMC) & & & & & & & \\
\hline Black vs. White (M) & 0.64 & 0.65 & $0.26,1.65$ & 0.36 & 1.13 & $0.51,2.52$ & 0.76 \\
\hline Hispanic vs. White (M) & 0.96 & 1.06 & $0.46,2.47$ & 0.88 & 0.90 & $0.39,2.06$ & 0.80 \\
\hline Black vs. White $(\mathrm{F})$ & 0.18 & 0.50 & $0.22,1.14$ & 0.10 & 0.66 & $0.35,1.25$ & 0.20 \\
\hline Hispanic vs. White $(\mathrm{F})$ & 0.77 & 0.85 & $0.42,1.70$ & 0.64 & 1.09 & $0.56,2.12$ & 0.79 \\
\hline Physical facility (CBOC) & & & & & & & \\
\hline Black vs. White (M) & 0.13 & 0.33 & $0.06,1.74$ & 0.19 & 2.11 & $0.70,6.36$ & 0.19 \\
\hline Hispanic vs. White (M) & 0.48 & 0.65 & $0.19,2.16$ & 0.48 & 1.72 & $0.60,4.90$ & 0.31 \\
\hline Black vs. White (F) & 0.75 & 1.66 & $0.43,6.38$ & 0.46 & 0.91 & $0.34,2.43$ & 0.85 \\
\hline
\end{tabular}


Table 4. (continued)

\begin{tabular}{|c|c|c|c|c|c|c|c|}
\hline \multirow[t]{2}{*}{$\overline{\text { Domain of Health Care (Gender) }}$} & \multirow{2}{*}{$\begin{array}{l}\text { Overall } \\
P \text { Value }\end{array}$} & \multicolumn{3}{|c|}{ Less than Satisfied vs. Very Satisfied } & \multicolumn{3}{|c|}{ Somewhat Satisfied vs. Very Satisfied } \\
\hline & & $\overline{\mathbf{R R R}}$ & $95 \% \mathrm{CI}$ & $P$ Value & $\overline{\mathrm{RRR}}$ & $95 \% \mathrm{CI}$ & $P$ Value \\
\hline \multirow{2}{*}{\multicolumn{8}{|c|}{ Cost of care }} \\
\hline & & & & & & & \\
\hline Black vs. White (M) & 0.83 & 1.39 & $0.48,4.00$ & 0.54 & 1.01 & $0.36,2.87$ & 0.98 \\
\hline Hispanic vs. White (M) & 0.08 & 1.38 & $0.51,3.69$ & 0.53 & 2.75 & $1.13,6.72$ & 0.03 \\
\hline Black vs. White (F) & 0.64 & 1.17 & $0.43,3.23$ & 0.76 & 0.70 & $0.30,1.60$ & 0.40 \\
\hline Hispanic vs. White $(\mathrm{F})$ & 0.37 & 1.75 & $0.70,4.35$ & 0.23 & 1.43 & $0.72,2.84$ & 0.30 \\
\hline \multicolumn{8}{|l|}{ Inpatient care } \\
\hline Black vs. White (M) & 0.86 & 1.07 & $0.21,5.40$ & 0.93 & 0.72 & $0.20,2.60$ & 0.62 \\
\hline Hispanic vs. White (M) & 0.94 & 0.80 & $0.15,4.45$ & 0.80 & 0.88 & $0.29,2.66$ & 0.82 \\
\hline Black vs. White $(\mathrm{F})$ & 0.44 & 0.48 & $0.14,1.68$ & 0.25 & 0.60 & $0.20,1.77$ & 0.35 \\
\hline Hispanic vs. White (F) & 0.41 & 1.21 & $0.32,4.59$ & 0.78 & 0.49 & $0.14,1.71$ & 0.26 \\
\hline \multicolumn{8}{|l|}{ Women's health } \\
\hline Black vs. White $(\mathrm{F})$ & 0.79 & 0.90 & $0.48,1.70$ & 0.75 & 1.19 & $0.64,2.22$ & 0.57 \\
\hline Hispanic vs. White (F) & 0.87 & 0.86 & $0.43,1.73$ & 0.67 & 1.06 & $0.59,1.88$ & 0.85 \\
\hline
\end{tabular}

Abbreviations: VAMC=Veterans Affairs Medical Center, CBOC=Community-Based Outpatient Clinic. Satisfaction with women's health was asked only of females Veterans 
Appendix 6

Table 5 Race/ethnicity-specific comparisons of health care satisfaction by gender. The set of Relative Rate Ratios (RRRs) for each domain compare the race/ethnicity-specific RRs of reporting "less than satisfied" versus "very satisfied" (left entry) and the RRs of reporting being "somewhat satisfied" versus "very satisfied" (right entry). RRRs to the left of 1.0 favor female Veterans being "very satisfied" relative to male Veterans of the same race/ethnicity

\begin{tabular}{|c|c|c|c|c|c|c|c|}
\hline \multirow[t]{2}{*}{$\overline{\text { Domain of Health Care }}$} & \multirow{2}{*}{$\begin{array}{l}\text { Overall } \\
P \text { Value }\end{array}$} & \multicolumn{3}{|c|}{ Less than Satisfied vs. Very Satisfied } & \multicolumn{3}{|c|}{ Somewhat Satisfied vs. Very Satisfied } \\
\hline & & $\overline{\mathbf{R R R}}$ & $95 \% \mathrm{CI}$ & $P$ Value & $\overline{\mathbf{R R R}}$ & $95 \% \mathrm{CI}$ & $P$ Value \\
\hline \multicolumn{8}{|l|}{ Overall care } \\
\hline White female vs. male & 0.39 & 1.84 & $0.77,4.39$ & 0.17 & 1.17 & $0.59,2.34$ & 0.65 \\
\hline Black female vs. male & 0.98 & 1.01 & $0.47,2.18$ & 0.98 & 1.07 & $0.54,2.12$ & 0.85 \\
\hline Hispanic female vs. male & 0.97 & 0.92 & $0.44,1.93$ & 0.82 & 1.00 & $0.58,1.72$ & 0.99 \\
\hline \multicolumn{8}{|l|}{ Outpatient care } \\
\hline White female vs. male & 0.08 & 1.25 & $0.50,3.11$ & 0.63 & 2.00 & $1.08,3.70$ & 0.03 \\
\hline Black female vs. male & 0.19 & 1.54 & $0.73,3.27$ & 0.26 & 1.49 & $0.93,2.38$ & 0.10 \\
\hline Hispanic female vs. male & 0.76 & 1.32 & $0.62,2.79$ & 0.47 & 0.99 & $0.57,1.71$ & 0.97 \\
\hline \multicolumn{8}{|l|}{ Primary care provider } \\
\hline White female vs. male & 0.50 & 1.15 & $0.49,2.71$ & 0.75 & 1.60 & $0.73,3.52$ & 0.24 \\
\hline Black female vs. male & 0.42 & 1.45 & $0.76,2.79$ & 0.26 & 1.24 & $0.57,2.69$ & 0.59 \\
\hline Hispanic female vs. male & 0.57 & 1.35 & $0.57,3.17$ & 0.50 & 0.75 & $0.35,1.61$ & 0.46 \\
\hline \multicolumn{8}{|l|}{ Specialist } \\
\hline White female vs. male & 0.70 & 1.47 & $0.59,3.65$ & 0.41 & 1.13 & $0.54,2.36$ & 0.74 \\
\hline Black female vs. male & 0.06 & 0.90 & $0.42,1.91$ & 0.78 & 0.49 & $0.27,0.89$ & 0.02 \\
\hline Hispanic female vs. male & 0.27 & 1.65 & $0.76,3.57$ & 0.21 & 1.45 & $0.71,2.96$ & 0.31 \\
\hline \multicolumn{8}{|l|}{ Mental health care } \\
\hline White female vs. male & 0.78 & 0.73 & $0.31,1.74$ & 0.48 & 0.91 & $0.40,2.07$ & 0.81 \\
\hline Black female vs. male & 0.21 & 0.48 & $0.20,1.13$ & 0.09 & 1.14 & $0.53,2.45$ & 0.74 \\
\hline Hispanic female vs. male & 0.22 & 0.82 & $0.41,1.64$ & 0.57 & 2.21 & $0.79,6.20$ & 0.13 \\
\hline \multicolumn{8}{|l|}{ Pain management } \\
\hline White female vs. male & 0.47 & 1.71 & $0.76,3.83$ & 0.19 & 1.15 & $0.58,2.31$ & 0.69 \\
\hline Black female vs. male & 0.18 & 0.84 & $0.37,1.88$ & 0.67 & 0.61 & $0.36,1.05$ & 0.07 \\
\hline Hispanic female vs. male & 0.26 & 1.60 & $0.83,3.08$ & 0.16 & 0.82 & $0.42,1.62$ & 0.57 \\
\hline \multicolumn{8}{|l|}{ Access } \\
\hline White female vs. male & 0.67 & 1.39 & $0.66,2.96$ & 0.39 & 1.17 & $0.72,1.89$ & 0.53 \\
\hline Black female vs. male & 0.13 & 2.01 & $0.97,4.14$ & 0.06 & 1.46 & $0.79,2.71$ & 0.22 \\
\hline Hispanic female vs. male & 0.61 & 0.90 & $0.46,1.78$ & 0.76 & 1.22 & $0.66,2.25$ & 0.53 \\
\hline \multicolumn{8}{|l|}{ Pharmacy } \\
\hline White female vs. male & 0.33 & 1.29 & $0.52,3.16$ & 0.58 & 1.62 & $0.85,3.08$ & 0.15 \\
\hline Black female vs. male & 0.08 & 2.98 & $1.10,8.07$ & 0.03 & 1.09 & $0.57,2.09$ & 0.80 \\
\hline Hispanic female vs. male & 0.29 & 1.23 & $0.57,2.68$ & 0.60 & 0.59 & $0.27,1.31$ & 0.20 \\
\hline \multicolumn{8}{|l|}{ Coordination of care } \\
\hline White female vs. male & 0.22 & 1.51 & $0.83,2.76$ & 0.18 & 1.64 & $0.86,3.12$ & 0.13 \\
\hline Black female vs. male & 0.49 & 1.45 & $0.76,2.78$ & 0.26 & 0.98 & $0.50,1.93$ & 0.95 \\
\hline Hispanic female vs. male & 0.25 & 1.76 & $0.91,3.40$ & 0.09 & 1.04 & $0.62,1.74$ & 0.89 \\
\hline \multicolumn{8}{|l|}{ Communication } \\
\hline White female vs. male & 0.39 & 1.48 & $0.75,2.92$ & 0.25 & 0.82 & $0.40,1.66$ & 0.58 \\
\hline Black female vs. male & 0.56 & 1.11 & $0.60,2.05$ & 0.75 & 1.39 & $0.76,2.55$ & 0.29 \\
\hline Hispanic female vs. male & 0.69 & 1.26 & $0.62,2.58$ & 0.52 & 1.30 & $0.68,2.52$ & 0.43 \\
\hline Respect & & & & & & & \\
\hline White female vs. male & 0.11 & 2.52 & $1.04,6.09$ & 0.04 & 1.30 & $0.64,2.65$ & 0.46 \\
\hline Black female vs. male & 0.27 & 1.86 & $0.84,4.10$ & 0.12 & 1.71 & $0.73,3.96$ & 0.21 \\
\hline Hispanic female vs. male & 0.60 & 1.45 & $0.68,3.07$ & 0.34 & 0.90 & $0.48,1.70$ & 0.75 \\
\hline Physical facility (VAMC) & & & & & & & \\
\hline White female vs. male & 0.21 & 1.94 & $0.84,4.48$ & 0.12 & 1.36 & $0.63,2.92$ & 0.43 \\
\hline Black female vs. male & 0.58 & 1.49 & $0.51,4.33$ & 0.46 & 0.79 & $0.39,1.62$ & 0.52 \\
\hline Hispanic female vs. male & 0.24 & 1.54 & $0.74,3.21$ & 0.25 & 1.66 & $0.85,3.24$ & 0.14 \\
\hline Physical facility (CBOC) & & & & & & & \\
\hline White female vs. male & 0.18 & 0.51 & $0.14,1.87$ & 0.31 & 2.46 & $0.84,7.23$ & 0.10 \\
\hline Black female vs. male & 0.60 & 2.59 & $0.40,16.77$ & 0.32 & 1.06 & $0.40,2.84$ & 0.91 \\
\hline Hispanic female vs. male & 0.31 & 0.41 & $0.09,1.88$ & 0.25 & 1.53 & $0.63,3.70$ & 0.35 \\
\hline Cost of care & & & & & & & \\
\hline White female vs. male & 0.07 & 1.43 & $0.52,3.96$ & 0.49 & 2.46 & $1.13,5.38$ & 0.02 \\
\hline Black female vs. male & 0.69 & 1.21 & $0.36,4.07$ & 0.76 & 1.70 & $0.50,5.73$ & 0.40 \\
\hline Hispanic female vs. male & 0.52 & 1.81 & $0.65,5.04$ & 0.25 & 1.28 & $0.50,3.31$ & 0.61 \\
\hline Inpatient care & & & & & & & \\
\hline White female vs. male & 0.46 & 2.28 & $0.52,10.09$ & 0.28 & 1.76 & $0.53,5.88$ & 0.36 \\
\hline Black female vs. male & 0.83 & 1.03 & $0.25,4.15$ & 0.97 & 1.46 & $0.42,5.03$ & 0.55 \\
\hline Hispanic female vs. male & 0.39 & 3.44 & $0.58,20.36$ & 0.17 & 0.99 & $0.29,3.31$ & 0.98 \\
\hline
\end{tabular}

Abbreviations: VAMC=Veterans Affairs Medical Center, $C B O C=$ Community-Based Outpatient Clinic 
Appendix 7

Table 6 Gender-specific comparisons of health care satisfaction by race/ethnicity, with domain-specific covariate adjustment. The set of Relative Rate Ratios (RRRs) for each domain compare the gender-specific RRs of reporting "less than satisfied" versus "very satisfied" (left entry) and the RRs of reporting being "somewhat satisfied" versus "very satisfied" (right entry). RRRs to the left of 1.0 favor Black (or Hispanic) Veterans being "very satisfied" relative to White Veterans of the same gender

\begin{tabular}{|c|c|c|c|c|c|c|c|}
\hline \multirow[t]{2}{*}{ Domain of Health Care (Gender) } & \multirow{2}{*}{$\frac{\text { Overall }}{P \text { Value }}$} & \multicolumn{3}{|c|}{ Less than Satisfied vs. Very Satisfied } & \multicolumn{3}{|c|}{ Somewhat Satisfied vs. Very Satisfied } \\
\hline & & $\overline{\mathbf{R R R}}$ & $95 \% \mathrm{CI}$ & $P$ Value & $\overline{\mathbf{R R R}}$ & $95 \% \mathrm{CI}$ & $P$ Value \\
\hline \multicolumn{8}{|l|}{ Overall care $^{\mathrm{a}}$} \\
\hline Black vs. White (M) & 0.69 & 1.51 & $0.57,4.00$ & 0.40 & 1.07 & $0.55,2.09$ & 0.84 \\
\hline Hispanic vs. White (M) & 0.82 & 1.15 & $0.51,2.61$ & 0.74 & 0.87 & $0.47,1.64$ & 0.68 \\
\hline Black vs. White $(\mathrm{F})$ & 0.71 & 0.74 & $0.33,1.66$ & 0.46 & 0.96 & $0.51,1.78$ & 0.89 \\
\hline Hispanic vs. White (F) & 0.34 & 0.55 & $0.23,1.28$ & 0.16 & 0.75 & $0.43,1.32$ & 0.32 \\
\hline \multicolumn{8}{|l|}{ Outpatient care $^{\text {b }}$} \\
\hline Black vs. White (M) & 0.19 & 0.78 & $0.30,2.04$ & 0.61 & 1.76 & $0.92,3.37$ & 0.09 \\
\hline Hispanic vs. White (M) & 0.28 & 1.00 & $0.42,2.39$ & 1.00 & 1.76 & $0.88,3.54$ & 0.11 \\
\hline Black vs. White $(\mathrm{F})$ & 0.58 & 0.82 & $0.40,1.68$ & 0.58 & 1.19 & $0.66,2.15$ & 0.55 \\
\hline Hispanic vs. White $(\mathrm{F})$ & 0.92 & 0.98 & $0.45,2.13$ & 0.95 & 0.87 & $0.46,1.66$ & 0.68 \\
\hline \multicolumn{8}{|l|}{ Primary care provider ${ }^{\mathrm{c}}$} \\
\hline Black vs. White (M) & 0.29 & 0.98 & $0.41,2.33$ & 0.97 & 1.75 & $0.86,3.55$ & 0.12 \\
\hline Hispanic vs. White (M) & 0.57 & 0.96 & $0.42,2.22$ & 0.92 & 1.65 & $0.65,4.23$ & 0.29 \\
\hline Black vs. White $(\mathrm{F})$ & 0.85 & 1.09 & $0.48,2.48$ & 0.83 & 1.22 & $0.60,2.47$ & 0.59 \\
\hline Hispanic vs. White (F) & 0.56 & 0.76 & $0.33,1.78$ & 0.53 & 0.71 & $0.35,1.46$ & 0.35 \\
\hline \multicolumn{8}{|l|}{ Specialist ${ }^{\mathrm{d}}$} \\
\hline Black vs. White (M) & 0.29 & 1.75 & $0.69,4.45$ & 0.24 & 1.55 & $0.79,3.05$ & 0.21 \\
\hline Hispanic vs. White (M) & 0.89 & 1.20 & $0.43,3.37$ & 0.73 & 0.92 & $0.45,1.91$ & 0.83 \\
\hline Black vs. White $(\mathrm{F})$ & 0.40 & 0.89 & $0.41,1.92$ & 0.77 & 0.64 & $0.33,1.23$ & 0.18 \\
\hline Hispanic vs. White (F) & 0.88 & 1.22 & $0.53,2.85$ & 0.64 & 1.13 & $0.52,2.48$ & 0.76 \\
\hline \multicolumn{8}{|l|}{ Mental health care } \\
\hline Black vs. White (M) & 0.87 & 1.10 & $0.40,3.05$ & 0.85 & 1.27 & $0.50,3.25$ & 0.61 \\
\hline Hispanic vs. White (M) & 0.79 & 0.77 & $0.32,1.85$ & 0.56 & 0.76 & $0.25,2.24$ & 0.61 \\
\hline Black vs. White $(\mathrm{F})$ & 0.23 & 0.64 & $0.28,1.46$ & 0.29 & 1.47 & $0.66,3.29$ & 0.35 \\
\hline Hispanic vs. White (F) & 0.42 & 0.81 & $0.36,1.80$ & 0.60 & 1.57 & $0.70,3.55$ & 0.27 \\
\hline \multicolumn{8}{|l|}{ Pain management $\mathrm{f}^{\mathrm{f}}$} \\
\hline Black vs. White (M) & 0.20 & 1.60 & $0.62,4.10$ & 0.33 & 1.94 & $0.92,4.07$ & 0.08 \\
\hline Hispanic vs. White (M) & 0.97 & 0.99 & $0.41,2.42$ & 0.98 & 0.92 & $0.41,2.09$ & 0.85 \\
\hline Black vs. White (F) & 0.82 & 0.77 & $0.31,1.87$ & 0.56 & 0.99 & $0.53,1.83$ & 0.97 \\
\hline Hispanic vs. White (F) & 0.62 & 1.02 & $0.44,2.32$ & 0.97 & 0.67 & $0.28,1.61$ & 0.37 \\
\hline \multicolumn{8}{|l|}{ Access $^{\mathrm{g}}$} \\
\hline Black vs. White (M) & 0.06 & 0.48 & $0.24,0.96$ & 0.04 & 0.61 & $0.33,1.14$ & 0.12 \\
\hline Hispanic vs. White (M) & 0.61 & 0.81 & $0.42,1.57$ & 0.53 & 0.73 & $0.39,1.38$ & 0.33 \\
\hline Black vs. White $(\mathrm{F})$ & 0.46 & 0.64 & $0.32,1.30$ & 0.22 & 0.76 & $0.40,1.43$ & 0.40 \\
\hline Hispanic vs. White (F) & 0.08 & 0.48 & $0.26,0.91$ & 0.02 & 0.81 & $0.45,1.44$ & 0.47 \\
\hline \multicolumn{8}{|l|}{ Pharmacy $^{\text {h }}$} \\
\hline Black vs. White (M) & 0.33 & 0.54 & $0.18,1.59$ & 0.26 & 1.29 & $0.71,2.34$ & 0.40 \\
\hline Hispanic vs. White (M) & 0.64 & 1.31 & $0.50,3.42$ & 0.58 & 1.36 & $0.67,2.75$ & 0.39 \\
\hline Black vs. White (F) & 0.58 & 1.43 & $0.59,3.47$ & 0.43 & 0.89 & $0.45,1.73$ & 0.72 \\
\hline Hispanic vs. White (F) & 0.06 & 1.39 & $0.52,3.73$ & 0.51 & 0.49 & $0.25,0.96$ & 0.04 \\
\hline Coordination of care ${ }^{i}$ & & & & & & & \\
\hline Black vs. White (M) & 0.06 & 0.66 & $0.36,1.22$ & 0.18 & 1.54 & $0.85,2.79$ & 0.15 \\
\hline Hispanic vs. White (M) & 0.09 & 0.67 & $0.38,1.18$ & 0.16 & 1.57 & $0.93,2.66$ & 0.09 \\
\hline Black vs. White $(\mathrm{F})$ & 0.25 & 0.52 & $0.23,1.19$ & 0.12 & 0.81 & $0.38,1.71$ & 0.58 \\
\hline Hispanic vs. White (F) & 0.54 & 0.73 & $0.41,1.32$ & 0.30 & 0.96 & $0.56,1.63$ & 0.88 \\
\hline Communication ${ }^{\mathrm{j}}$ & & & & & & & \\
\hline Black vs. White (M) & 0.81 & 1.05 & $0.49,2.25$ & 0.90 & 0.83 & $0.44,1.56$ & 0.56 \\
\hline Hispanic vs. White (M) & 0.78 & 0.90 & $0.44,1.84$ & 0.78 & 0.78 & $0.38,1.58$ & 0.49 \\
\hline Black vs. White (F) & 0.32 & 0.65 & $0.28,1.48$ & 0.30 & 1.27 & $0.72,2.23$ & 0.40 \\
\hline Hispanic vs. White $(\mathrm{F})$ & 0.41 & 0.67 & $0.31,1.43$ & 0.30 & 1.12 & $0.61,2.08$ & 0.71 \\
\hline Respect $^{\mathrm{k}}$ & & & & & & & \\
\hline Black vs. White (M) & 0.50 & 1.82 & $0.66,5.05$ & 0.25 & 1.28 & $0.56,2.92$ & 0.56 \\
\hline Hispanic vs. White (M) & 0.56 & 1.51 & $0.58,3.94$ & 0.40 & 1.34 & $0.67,2.66$ & 0.41 \\
\hline Black vs. White $(\mathrm{F})$ & 0.42 & 1.17 & $0.58,2.37$ & 0.67 & 1.57 & $0.79,3.10$ & 0.20 \\
\hline Hispanic vs. White $(\mathrm{F})$ & 0.97 & 0.93 & $0.47,1.86$ & 0.84 & 0.93 & $0.44,1.94$ & 0.84 \\
\hline Physical facility (VAMC) ${ }^{1}$ & & & & & & & \\
\hline Black vs. White (M) & 0.57 & 0.60 & $0.21,1.73$ & 0.35 & 1.26 & $0.57,2.77$ & 0.57 \\
\hline Hispanic vs. White (M) & 0.99 & 1.06 & $0.43,2.61$ & 0.90 & 1.02 & $0.44,2.38$ & 0.96 \\
\hline Black vs. White (F) & 0.11 & 0.40 & $0.16,1.00$ & 0.05 & 0.59 & $0.29,1.19$ & 0.14 \\
\hline Hispanic vs. White (F) & 0.78 & 0.84 & $0.39,1.78$ & 0.64 & 1.11 & $0.57,2.18$ & 0.76 \\
\hline Physical facility $(\mathrm{CBOC})^{\mathrm{m}}$ & & & & & & & \\
\hline Black vs. White (M) & 0.12 & 0.32 & $0.06,1.66$ & 0.17 & 2.14 & $0.69,6.64$ & 0.19 \\
\hline Hispanic vs. White (M) & 0.50 & 0.63 & $0.20,2.03$ & 0.44 & 1.64 & $0.56,4.83$ & 0.37 \\
\hline Black vs. White $(\mathrm{F})$ & 0.73 & 1.63 & $0.42,6.41$ & 0.48 & 0.83 & $0.30,2.30$ & 0.72 \\
\hline Hispanic vs. White (F) & 0.72 & 0.51 & $0.10,2.66$ & 0.42 & 0.99 & $0.40,2.48$ & 0.98 \\
\hline
\end{tabular}


Table 6. (continued)

\begin{tabular}{|c|c|c|c|c|c|c|c|}
\hline \multirow[t]{2}{*}{ Domain of Health Care (Gender) } & \multirow{2}{*}{$\frac{}{P \text { Overall }}$} & \multicolumn{3}{|c|}{ Less than Satisfied vs. Very Satisfied } & \multicolumn{3}{|c|}{ Somewhat Satisfied vs. Very Satisfied } \\
\hline & & $\overline{\mathbf{R R R}}$ & $95 \% \mathrm{CI}$ & $P$ Value & $\overline{\mathbf{R R R}}$ & $95 \% \mathrm{CI}$ & $P$ Value \\
\hline \multicolumn{8}{|l|}{ Cost of care ${ }^{\mathrm{n}}$} \\
\hline Black vs. White (M) & 0.91 & 1.27 & $0.43,3.76$ & 0.66 & 1.06 & $0.38,2.96$ & 0.92 \\
\hline Hispanic vs. White (M) & 0.09 & 1.43 & $0.50,4.10$ & 0.50 & 2.84 & $1.12,7.19$ & 0.03 \\
\hline Black vs. White (F) & 0.60 & 0.90 & $0.30,2.69$ & 0.85 & 0.65 & $0.29,1.50$ & 0.32 \\
\hline Hispanic vs. White (F) & 0.43 & 1.70 & $0.65,4.45$ & 0.28 & 1.37 & $0.69,2.70$ & 0.37 \\
\hline \multicolumn{8}{|l|}{ Inpatient care ${ }^{\circ}$} \\
\hline Black vs. White (M) & 0.95 & 1.33 & $0.23,7.70$ & 0.75 & 0.98 & $0.25,3.80$ & 0.98 \\
\hline Hispanic vs. White (M) & 0.90 & 0.99 & $0.13,7.52$ & 0.99 & 1.34 & $0.39,4.61$ & 0.64 \\
\hline Black vs. White $(\mathrm{F})$ & 0.43 & 0.42 & $0.11,1.58$ & 0.20 & 0.74 & $0.22,2.42$ & 0.62 \\
\hline Hispanic vs. White (F) & 0.48 & 1.15 & $0.27,4.89$ & 0.85 & 0.50 & $0.14,1.86$ & 0.30 \\
\hline \multicolumn{8}{|l|}{ Women's health ${ }^{\mathrm{p}}$} \\
\hline Black vs. White $(\mathrm{F})$ & 0.64 & 0.84 & $0.40,1.76$ & 0.64 & 1.15 & $0.58,2.25$ & 0.69 \\
\hline Hispanic vs. White (F) & 0.69 & 0.86 & $0.40,1.76$ & 0.69 & 1.05 & $0.58,1.92$ & 0.87 \\
\hline
\end{tabular}

Abbreviations: VAMC=Veterans Affairs Medical Center, $C B O C=$ Community-Based Outpatient Clinic

Domain-specific adjustment:

${ }^{a}$ Overall: Health status, health compared to 1 year ago, depression, PTSD or anxiety disorder, receive all health care at VA and had $\geq 1$ MH visit in the past 12 months

${ }^{b}$ Outpatient: Education, health status, health compared to 1 year ago, diabetes, receive all health care at VA and number of PCP visits in the past 12 months

${ }^{c} P C P$ : Income, health status, health compared to 1 year ago, and receive all health care at VA

${ }^{d}$ Specialist: Number of adults, health status, health compared to 1 year ago, and receive all health care at VA

${ }^{e}$ Mental Health: Health status, health compared to 1 year ago, depression, receive all health care at VA and had $\geq 1$ MH visit in the past 12 months

Pain: Health status, health compared to 1 year ago, depression, receive all health care at VA, received treatment for pain in last 24 months and had $\geq 1$ outpatient visits in the past 12 months

${ }^{g}$ Access: Health status, health compared to 1 year ago, health literacy, depression and receive all health care at VA

${ }^{h}$ Pharmacy: Health status, health compared to 1 year ago, health literacy, asthma and receive all health care at VA

${ }^{i}$ Coordination of Care: Health status, health compared to 1 year ago, depression and receive all health care at VA;

${ }^{j}$ Communication: Health status, health compared to 1 year ago, digestive or GI problems and receive all health care at VA

${ }^{k}$ Respect: Education, number of adults, health status, health compared to 1 year ago, health literacy, depression and receive all health care at VA

'Physical facility (VAMC): Education, employment status, health status, health compared to 1 year ago and receive all health care at VA

${ }^{m}$ Physical facility $(C B O C)$ : Health status, health compared to 1 year ago and receive all health care at VA

${ }^{n}$ Cost: Place of residence, health status, health compared to 1 year ago and receive all health care at VA

'Inpatient: Post-Vietnam, health status, health compared to 1 year ago and receive all health care at VA

${ }^{p}$ Women's Health: Employment status, number of adults, health status, health compared to 1 year ago, kidney disease, PTSD or anxiety disorder, receive all health care at VA and had $\geq 1 P P$ visit in the past 12 months 
Appendix 8

Table 7 Race/ethnicity-specific comparisons of health care satisfaction by gender, with domain-specific covariate adjustment. The set of Relative Rate Ratios (RRRs) for each domain compare the race/ethnicity-specific RRs of reporting "less than satisfied" versus "very satisfied" (left entry) and the RRs of reporting being "somewhat satisfied" versus "very satisfied" (right entry). RRRs to the left of 1.0 favor female Veterans being "very satisfied" relative to male Veterans of the same race/ethnicity

\begin{tabular}{|c|c|c|c|c|c|c|c|}
\hline \multirow[t]{2}{*}{ Domain of Health Care } & \multirow{2}{*}{$\begin{array}{l}\text { Overall } \\
P \text { Value }\end{array}$} & \multicolumn{3}{|c|}{ Less than Satisfied vs. Very Satisfied } & \multicolumn{3}{|c|}{ Somewhat Satisfied vs. Very Satisfied } \\
\hline & & $\overline{\mathbf{R R R}}$ & $95 \% \mathrm{CI}$ & $P$ Value & $\overline{\mathbf{R R R}}$ & $95 \% \mathrm{CI}$ & $P$ Value \\
\hline \multicolumn{8}{|l|}{ Overall care $^{\mathrm{a}}$} \\
\hline White female vs. male & 0.44 & 1.80 & $0.72,4.49$ & 0.21 & 1.12 & $0.53,2.38$ & 0.76 \\
\hline Black female vs. male & 0.94 & 0.88 & $0.36,2.11$ & 0.77 & 1.00 & $0.48,2.09$ & 1.00 \\
\hline Hispanic female vs. male & 0.93 & 0.86 & $0.39,1.89$ & 0.70 & 0.97 & $0.56,1.67$ & 0.91 \\
\hline \multicolumn{8}{|l|}{ Outpatient care ${ }^{\mathrm{b}}$} \\
\hline White female vs. male & 0.13 & 1.19 & $0.46,3.13$ & 0.72 & 1.94 & $1.01,3.73$ & 0.05 \\
\hline Black female vs. male & 0.58 & 1.26 & $0.54,2.95$ & 0.60 & 1.32 & $0.79,2.19$ & 0.29 \\
\hline Hispanic female vs. male & 0.92 & 1.17 & $0.49,2.78$ & 0.73 & 0.96 & $0.57,1.61$ & 0.88 \\
\hline \multicolumn{8}{|l|}{ Primary care provider ${ }^{\mathrm{c}}$} \\
\hline White female vs. male & 0.35 & 1.31 & $0.55,3.10$ & 0.54 & 1.78 & $0.80,4.00$ & 0.16 \\
\hline Black female vs. male & 0.55 & 1.46 & $0.67,3.19$ & 0.35 & 1.24 & $0.56,2.78$ & 0.60 \\
\hline Hispanic female vs. male & 0.79 & 1.04 & $0.42,2.59$ & 0.94 & 0.77 & $0.34,1.71$ & 0.52 \\
\hline \multicolumn{8}{|l|}{ Specialist $\mathrm{d}^{\mathrm{d}}$} \\
\hline White female vs. male & 0.67 & 1.56 & $0.59,4.15$ & 0.37 & 1.10 & $0.52,2.34$ & 0.80 \\
\hline Black female vs. male & 0.03 & 0.80 & $0.36,1.78$ & 0.58 & 0.45 & $0.24,0.84$ & 0.01 \\
\hline Hispanic female vs. male & 0.38 & 1.60 & $0.72,3.54$ & 0.25 & 1.35 & $0.64,2.85$ & 0.43 \\
\hline \multicolumn{8}{|l|}{ Mental health care $\mathrm{e}^{\mathrm{e}}$} \\
\hline White female vs. male & 0.83 & 0.76 & $0.31,1.84$ & 0.54 & 0.92 & $0.40,2.13$ & 0.85 \\
\hline Black female vs. male & 0.17 & 0.44 & $0.18,1.05$ & 0.06 & 1.07 & $0.49,2.32$ & 0.87 \\
\hline Hispanic female vs. male & 0.34 & 0.79 & $0.37,1.68$ & 0.54 & 1.92 & $0.67,5.48$ & 0.22 \\
\hline \multicolumn{8}{|l|}{ Pain management $\mathrm{f}^{\mathrm{f}}$} \\
\hline White female vs. male & 0.39 & 1.72 & $0.73,4.06$ & 0.22 & 1.13 & $0.52,2.43$ & 0.76 \\
\hline Black female vs. male & 0.11 & 0.82 & $0.34,1.98$ & 0.66 & 0.57 & $0.33,0.99$ & 0.05 \\
\hline Hispanic female vs. male & 0.21 & 1.76 & $0.84,3.70$ & 0.13 & 0.81 & $0.40,1.66$ & 0.57 \\
\hline \multicolumn{8}{|l|}{ Access ${ }^{\mathrm{g}}$} \\
\hline White female vs. male & 0.60 & 1.55 & $0.66,3.65$ & 0.31 & 1.17 & $0.68,2.02$ & 0.57 \\
\hline Black female vs. male & 0.17 & 2.10 & $0.92,4.79$ & 0.08 & 1.46 & $0.77,2.77$ & 0.24 \\
\hline Hispanic female vs. male & 0.50 & 0.93 & $0.44,1.95$ & 0.84 & 1.30 & $0.69,2.43$ & 0.41 \\
\hline \multicolumn{8}{|l|}{ Pharmacy $^{\mathrm{h}}$} \\
\hline White female vs. male & 0.16 & 1.67 & $0.89 ; 3.14$ & 0.11 & 1.74 & $0.90 ; 3.40$ & 0.10 \\
\hline Black female vs. male & 0.08 & 3.33 & $1.16 ; 9.54$ & 0.03 & 1.13 & $0.58,2.23$ & 0.08 \\
\hline Hispanic female vs. male & 0.26 & 1.32 & $0.60 ; 2.92$ & 0.49 & 0.59 & $0.27,1.29$ & 0.19 \\
\hline \multicolumn{8}{|l|}{ Coordination of care ${ }^{\mathrm{i}}$} \\
\hline White female vs. male & 0.16 & 1.67 & $0.89,3.14$ & 0.11 & 1.74 & $0.90,3.40$ & 0.10 \\
\hline Black female vs. male & 0.58 & 1.33 & $0.68,2.58$ & 0.41 & 0.91 & $0.45,1.86$ & 0.80 \\
\hline Hispanic female vs. male & 0.23 & 1.83 & $0.91,3.66$ & 0.09 & 1.06 & $0.63,1.81$ & 0.82 \\
\hline \multicolumn{8}{|l|}{ Communication $^{\mathrm{j}}$} \\
\hline White female vs. male & 0.48 & 1.49 & $0.69,3.22$ & 0.31 & 0.85 & $0.41,1.75$ & 0.65 \\
\hline Black female vs. male & 0.65 & 0.92 & $0.46,1.83$ & 0.81 & 1.30 & $0.69,2.47$ & 0.42 \\
\hline Hispanic female vs. male & 0.84 & 1.11 & $0.51,2.38$ & 0.80 & 1.22 & $0.63,2.38$ & 0.56 \\
\hline Respect $^{\mathrm{k}}$ & & & & & & & \\
\hline White female vs. male & 0.15 & 2.43 & $0.97,6.09$ & 0.06 & 1.33 & $0.62,2.83$ & 0.46 \\
\hline Black female vs. male & 0.49 & 1.56 & $0.63,3.87$ & 0.33 & 1.63 & $0.68,3.92$ & 0.28 \\
\hline Hispanic female vs. male & 0.63 & 1.50 & $0.63,3.55$ & 0.36 & 0.92 & $0.48,1.78$ & 0.81 \\
\hline Physical facility (VAMC) ${ }^{1}$ & & & & & & & \\
\hline White female vs. male & 0.24 & 1.82 & $0.75,4.39$ & 0.18 & 1.46 & $0.65,3.28$ & 0.36 \\
\hline Black female vs. male & 0.55 & 1.22 & $0.38,3.87$ & 0.74 & 0.68 & $0.31,1.49$ & 0.34 \\
\hline Hispanic female vs. male & 0.37 & 1.44 & $0.64,3.23$ & 0.38 & 1.58 & $0.78,3.21$ & 0.20 \\
\hline Physical facility $(\mathrm{CBOC})^{\mathrm{m}}$ & & & & & & & \\
\hline White female vs. male & 0.18 & 0.50 & $0.14,1.84$ & 0.30 & 2.49 & $0.83,7.44$ & 0.10 \\
\hline Black female vs. male & 0.58 & 2.58 & $0.40,16.49$ & 0.32 & 0.97 & $0.34,2.80$ & 0.96 \\
\hline Hispanic female vs. male & 0.33 & 0.41 & $0.08,1.95$ & 0.26 & 1.50 & $0.61,3.70$ & 0.38 \\
\hline Cost of care $\mathrm{e}^{\mathrm{n}}$ & & & & & & & \\
\hline White female vs. male & 0.06 & 1.60 & $0.53,4.81$ & 0.40 & 2.53 & $1.15,5.58$ & 0.02 \\
\hline Black female vs. male & 0.77 & 1.13 & $0.32,4.03$ & 0.85 & 1.57 & $0.46,5.34$ & 0.47 \\
\hline Hispanic female vs. male & 0.51 & 1.89 & $0.64,5.61$ & 0.25 & 1.22 & $0.47,3.20$ & 0.69 \\
\hline Inpatient care ${ }^{\mathrm{o}}$ & & & & & & & \\
\hline White female vs. male & 0.30 & 2.94 & $0.60,14.47$ & 0.18 & 2.19 & $0.57,8.35$ & 0.25 \\
\hline Black female vs. male & 0.70 & 0.92 & $0.22,3.94$ & 0.92 & 1.64 & $0.45,6.06$ & 0.45 \\
\hline Hispanic female vs. male & 0.39 & 3.42 & $0.57,20.60$ & 0.18 & 0.82 & $0.23,2.92$ & 0.76 \\
\hline
\end{tabular}

Abbreviations: VAMC=Veterans Affairs Medical Center, $C B O C=$ Community-Based Outpatient Clinic

Domain-specific adjustment:

${ }^{a}$ Overall: Health status, health compared to 1 year ago, depression, PTSD or anxiety disorder, receive all health care at VA and had $\geq 1$ MH visit in the past 12 months 
${ }^{b}$ Outpatient: Education, health status, health compared to 1 year ago, diabetes, receive all health care at VA and number of PCP visits in the past 12 months

${ }^{c} P C P$ : Income, health status, health compared to 1 year ago, and receive all health care at VA

${ }^{d}$ Specialist: Number of adults, health status, health compared to 1 year ago, and receive all health care at VA

${ }^{e}$ Mental Health: Health status, health compared to 1 year ago, depression, receive all health care at VA and had $\geq 1$ MH visit in the past 12 months

${ }^{f}$ Pain: Health status, health compared to 1 year ago, depression, receive all health care at VA, received treatment for pain in last 24 months and had $\geq$ outpatient visits in the past 12 months

${ }^{g}$ Access: Health status, health compared to 1 year ago, health literacy, depression and receive all health care at VA

${ }^{h}$ Pharmacy: Health status, health compared to 1 year ago, health literacy, asthma and receive all health care at VA

${ }^{i}$ Coordination of Care: Health status, health compared to 1 year ago, depression and receive all health care at VA

${ }^{j}$ Communication: Health status, health compared to 1 year ago, digestive or GI problems and receive all health care at VA

${ }^{k}$ Respect: Education, number of adults, health status, health compared to 1 year ago, health literacy, depression and receive all health care at VA

'Physical facility (VAMC): Education, employment status, health status, health compared to 1 year ago and receive all health care at VA

${ }^{m}$ Physical facility (CBOC): Health status, health compared to 1 year ago and receive all health care at VA

${ }^{n}$ Cost: Place of residence, health status, health compared to 1 year ago and receive all health care at VA

Inpatient: Post-Vietnam, health status, health compared to 1 year ago and receive all health care at VA 